\title{
Role of the mucins in pathogenesis of COPD: implications for therapy
}

Federica Lo Bello, Antonio leni, Philip M. Hansbro, Paolo Ruggeri, Antonino Di Stefano, Francesco Nucera, Irene Coppolino, Francesco Monaco, Giovanni Tuccari, Ian M. Adcock \& Gaetano Caramori

To cite this article: Federica Lo Bello, Antonio leni, Philip M. Hansbro, Paolo Ruggeri, Antonino Di Stefano, Francesco Nucera, Irene Coppolino, Francesco Monaco, Giovanni Tuccari, lan M. Adcock \& Gaetano Caramori (2020): Role of the mucins in pathogenesis of COPD: implications for therapy, Expert Review of Respiratory Medicine, DOI: 10.1080/17476348.2020.1739525

To link to this article: https://doi.org/10.1080/17476348.2020.1739525

Accepted author version posted online: 05 Mar 2020.

Submit your article to this journal ๘

山ll Article views: 4

Q View related articles ¿

View Crossmark data 
Publisher: Taylor \& Francis \& Informa UK Limited, trading as Taylor \& Francis Group

Journal: Expert Review of Respiratory Medicine

DOI: $10.1080 / 17476348.2020 .1739525$

Article type: Review

Role of the mucins in pathogenesis of COPD: implications for therapy

Federica Lo Bello ${ }^{1}$, Antonio Ieni ${ }^{2}$, Philip M. Hansbro ${ }^{3}$, Paolo Ruggeri ${ }^{1}$, Antonino Di

Stefano $^{4}$, Francesco Nucera ${ }^{1}$, Irene Coppolino ${ }^{1}$, Francesco Monaco ${ }^{5}$, Giovanni Tuccari ${ }^{2}$,

Ian M. Adcock ${ }^{6}$, Gaetano Caramori ${ }^{1}$

${ }^{1}$ Unità Operativa Complessa di Pneumologia, Dipartimento di Scienze Biomediche, Odontoiatriche e delle Immagini Morfologiche e Funzionali (BIOMORF), Università di Messina, Messina, Italy.

${ }^{2}$ Department of Human Pathology in Adult and Developmental Age "Gaetano Barresi", Section of Anatomic Pathology, University of Messina, Messina, Italy.

${ }^{3}$ Centre for Inflammation, Centenary Institute, Sydney, and University of Technology Sydney, Faculty of Science, Ultimo, NSW, Australia.

${ }^{4}$ Divisione di Pneumologia e Laboratorio di Citoimmunopatologia dell'Apparato Cardio Respiratorio, Istituti Clinici Scientifici Maugeri, IRCCS, Veruno (NO), Italy

${ }^{5}$ Unità Operativa Semplice Dipartimentale di Chirurgia Toracica, Dipartimento di Scienze Biomediche, Odontoiatriche e delle Immagini Morfologiche e Funzionali (BIOMORF), AOU Policlinico "G.Martino", Messina, Italy

${ }^{6}$ Airway Disease Section, National Heart and Lung Institute, Imperial College, London, UK.

*Corresponding Author:

Gaetano Caramori

Unità Operativa Complessa di Pneumologia

Dipartimento di Scienze Biomediche, Odontoiatriche e delle Immagini Morfologiche e

Funzionali (BIOMORF)

Università degli Studi di Messina

98122 Messina, Italy

Tel. +390902212000

E-mail: gcaramori@unime.it 


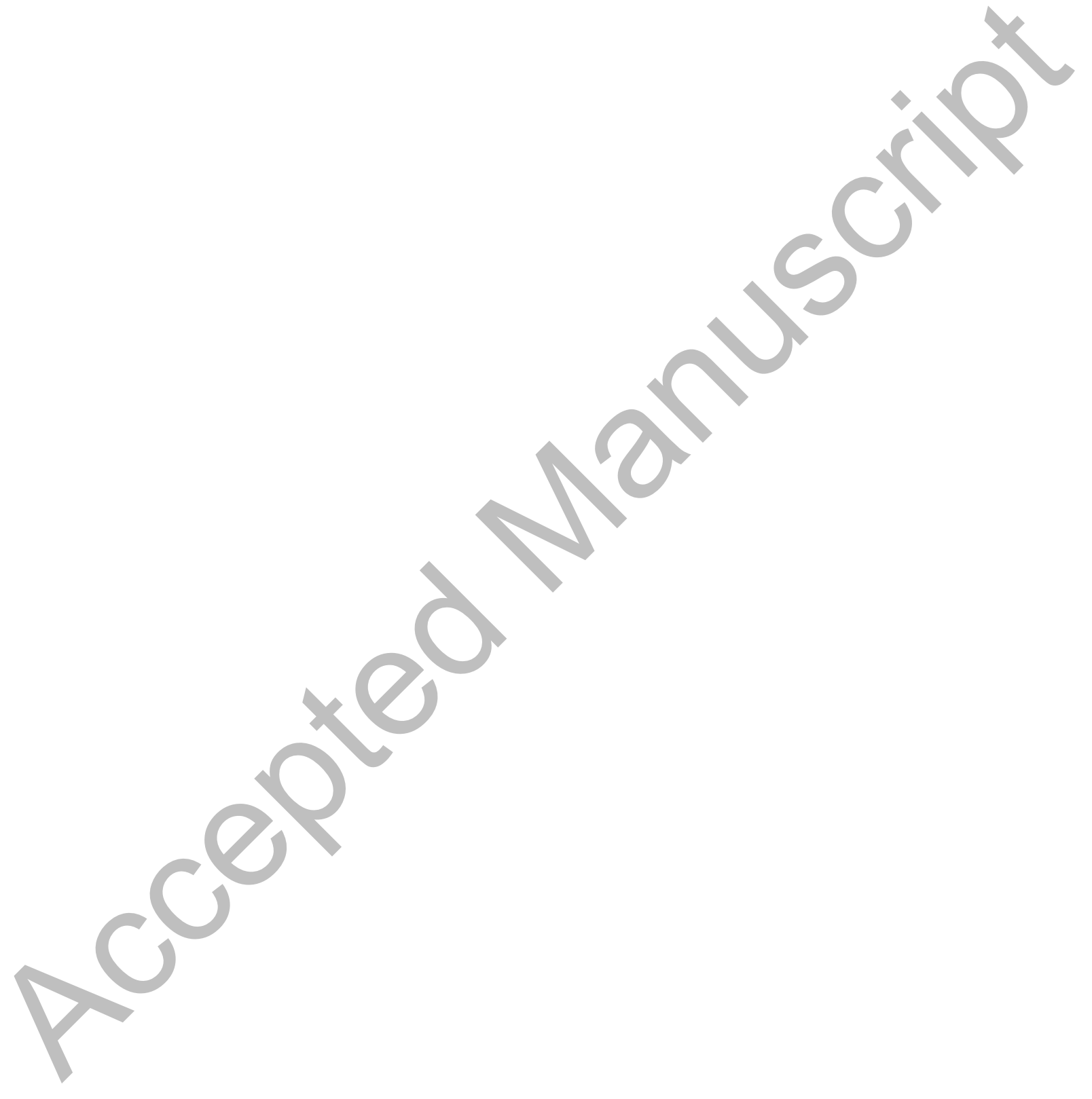




\section{Abstract}

Introduction: Evidence accumulated in the last decade has started to reveal the enormous complexity in the expression, interactions and functions of the large number of different mucins present in the different compartments of the human lower airways. This occurs both in normal subjects and in COPD patients in different clinical phases and stages of severity.

Areas covered: We review the known physiological mechanisms that regulate mucin production in human lower airways of normal subjects, the changes in mucin synthesis/secretion in COPD patients and the clinical efficacy of drugs that modulate mucin synthesis/secretion.

Expert opinion: It evident that the old simplistic concept that mucus hypersecretion in COPD patients is associated with negative clinical outcomes is valid and that the therapeutic potential of "mucolytic drugs" is under-appreciated due to the complexity of the associated molecular network(s). Likewise, our current knowledge of the effects of the drugs already available on the market that target mucin synthesis/secretion/structure in the lower airways is extremely limited and often indirect and more well-controlled clinical trials are needed in this area.

Key words: COPD, MUC5AC, MUC5B, infections, exacerbations, treatment, mucoactive drugs 


\section{Article Highlights}

- Changes in mucin gene expression and production, mucin degradation and dehydration of the mucus layer alter the physiological function of mucins in the human lower airways.

- Different pathogens, such as respiratory viruses and bacteria, may upregulate or downregulate mucin-secreting cell differentiation and mucin secretion.

- The large number of different mucins in the different compartments of the human lower airways are characterised by an enormous complexity of expression, interactions and functions both in normal subjects and in patients with COPD of different clinical phases and stages of severity.

- The pathogenic role of changes in mucin gene expression and production observed in the blood and/or lower airways of COPD patients requires more translational studies.

- The efficacy of mucin synthesis/secretion/structure modulators in the treatment of COPD remains controversial. 


\section{Introduction}

Here we review the physiological mechanisms that regulate mucin production in the human lower airways of normal subjects, the changes that occur in the synthesis/secretion of mucins in the lower airways of patients with chronic obstructive pulmonary disease (COPD) and the clinical efficacy of drugs that modulate their synthesis/secretion.

\section{Composition of the secretions of the human lower airways}

The normal volume of the human lower airways (tracheobronchial, pulmonary) secretions in the "healthy" subjects undergoing laryngectomy or tracheostomy is estimated to be between 10-100 ml per day or a maximum of $0.5 \mathrm{ml} / \mathrm{Kg}$ body weight/day [1, 2]. Only the secretions of the human lower airways that accumulate in the trachea can be expectorated by cough as sputum (or phlegm) because cough receptors are absent in human bronchioles. Under physiological conditions healthy subjects, without laryngectomy or tracheostomy, do not expectorate and for this reason these secretions are often termed erroneously "mucus" or "sputum", whilst in reality they are a complex aqueous solution, composed of $\sim 95 \%$ water, with the remaining made up of proteins, lipids, carbohydrate, deoxyribonucleic acid (DNA) and electrolytes [3].

\section{Transmembrane and secreted mucins of the human lower airways}

Mucins is a descriptive term for a family of glycoproteins with high molecular weight $(100-100,000$ $\mathrm{kDa}$ ) composed of $70-80 \%$ carbohydrates, $20 \%$ proteins, and $1-2 \%$ sulphate bound to oligosaccharide side chains [4]. All mucins share some common structural features, a protein domain of repeating sequences of amino acids rich in threonine and proline, a central carrier region (core) called apomucin, with multiple lateral chains of oligosaccharides (Figure 1). 
Apomucins are peptides that comprise $10-20 \%$ of the total weight of glycoproteins and are organized into two regions, a centrally located tandem repeat region rich in serine, threonine, and proline (STP-tandem repeats) and carboxy- and amino-terminal non-repeat regions. The latter may be rich in cysteine residues with low amounts of serine/threonine and relatively little Oglycosylated serine but possessing greater levels of $\mathrm{N}$-glycosylated residues [5]. Twenty-two human mucin genes have been identified (HUGO Gene Nomenclature Committee, www.genenames.org/cgi-bin/genefamilies/set/648) coding for apomucins and are named as "MUC" followed by a number that reflects the order in which the particular mucin gene was discovered. According to the standard rules of nomenclature all letters are capitalized for the human gene and the first letter is capitalized with all following letters lower case for mouse gene [6]. Several mucins have alleles with different lengths of repetitive sequences and varied numbers of tandem repeats. A deeper genomic analysis of the tandem repeat regions often show that there is only limited sequence conservation of these regions of orthologous genes between closely related species [7, 8]. The lack of sequence conservation means that the amino acid sequence is less important as long as there are a sufficiently high number of threonine and serine attachment sites for $\mathrm{N}$ acetylgalactosamine (GaINAc) and number of prolines to maintain an unfolded protein, making it accessible for glycosylation

Mucins are highly glycosylated and carbohydrates are primarily composed of GalNAc, Nacetylglucosamine (GlcNAc), fucose (Fuc), galactose (Gal) and sialic acids or NANA (N-acetyl neuraminic acid or NeuNAc) and small amounts of mannose and sulphate. The oligosaccharide chains possess 2-20 monosaccharides in both linear and branched structures [9]. A large proportion of the serine/threonine residues are glycosylated, resulting in a "bottle brush" configuration of the oligosaccharides arranged around the mucin protein core. These structures are directly observed by electron microscopy have molecular lengths of $50-1000 \mathrm{~nm}$ up to $8 \mu \mathrm{m}$ 
[10]. Based on the structure and localization, mucins can be divided into transmembrane and secreted mucins (Table 1).

The major mucins produced in the airways are the secreted polymeric mucins MUC5AC and MUC5B and the transmembrane mucins MUC1, MUC4, MUC16 and MUC20 [11]. Other than these, many other mucin genes have been found in the human lower airways, including MUC2, MUC 6, MUC7, MUC8, MUC13, MUC19, MUC21 and MUC22 [12-15].

\section{Genetic pathways modulating the synthesis/secretion of MUC5B in the human lower}

\section{airways}

The single-nucleotide polymorphism (SNP) rs35705950 in the promoter region of the human MUC5B gene potently regulates its expression [16-18]. The presence of the rs35705950 minor allele enhances transcription of $M U C 5 B$, increased mucin messenger ribonucleic acid (mRNA) production, especially in the distal airways where the SNP genotype correlates with MUC5B protein levels in the bronchioles in vivo and promoter activity in vitro [16, 19]. The rs 35705950 affects expression at baseline, with healthy subjects carrying either one or two copies of the minor allele expressing $\sim 40$-fold increased levels of MUC5B than major allele homozygotes [18]. The rs35705950 SNP is part of an active enhancer containing a FOXA2-binding site, suggesting that repression of MUC5B transcription by FOXA2 is lost when the gain-of-function SNP site is in an inactive state that potentially involves epigenetic control via methylation. Since rs35705950 regulates $\mathrm{MUC5B}$ expression under homeostatic conditions, the very high levels of expression imparted by this SNP may be detrimental in the long term. In contrast, no genetic links are evident for MUC5AC expression. 


\section{Assembly, storage and secretion of the major secreted polymeric mucins MUC5AC and MUC5B of the human lower airways}

The assembly, storage and secretion of the major secreted polymeric mucins MUC5AC and MUC5B involves a succession of steps in different intracellular and extracellular compartments (Table 2) [3]. After nuclear transcription, secreted mucins are co-translationally imported into the rough endoplasmic reticulum where dimers of mucin disulphide are assembled. Mucins are then folded and transported from the endoplasmic reticulum to the golgi complex; in the cis golgi, mucins are O-glycosylated by the addition of GalNAc by GalNAc-transferase (GALNTs). Mucins then pass through the central golgi where further structures are formed by the addition of GlcNAc and/or Gal.

Glycosylation of the mucins ends in sialylation via $\alpha 2,3-$ syalyltransferases or fucosylation via $\alpha 1,2$ enzymes [ST3 beta-galactoside alpha-2,3-sialyltransferase 3 (ST3GAL3) and galactoside 2-alphaL-fucosyltransferase 2 (FUT2)] and subsequently the oligomeric subunits of the mucins polymerize through the assembly of the $\mathrm{N}$-terminals [20]. The fully synthesised mucins are then transported by the trans-golgi by vesicular traffic to the growing secretory granules, where they are stored for possible release by regulated exocytosis [20].

\section{Epigenetic pathways modulating the synthesis/secretion of the major secreted polymeric mucins MUC5AC and MUC5B of the human lower airways}

Studies on epigenetic pathways modulating the synthesis/secretion of the mucins of the human lower airways remain limited. The known epigenetic pathways modulating in vitro and in vivo expression of MUC5AC and MUC5B, involving the DNA methylation and histone modification (acetylation or deacetylation) are summarised in Table 3. 
7. Mediators regulating the synthesis/secretion of the major secreted polymeric mucins MUC5AC and MUC5B of the human lower airways

There is little in vivo data are available on the regulation of activity of the mucin-secreting cells of the human lower airways. Theoretically, their activity can be modulated by different substances, acting directly on cell surface receptors or indirectly on receptors present on the external surface of the plasma membrane of myoepithelial cells located around the glands or on inhibitory/stimulant receptors located on type C fibres [20-22].

The inflammatory mediators that modulate the synthesis/secretion of mucins from primary tracheobronchial epithelium obtained from normal subjects in vitro are summarised in Table 4 [20, $23,24]$.

8. Physiological function of the epithelial lining fluid, mucociliary clearance and the major secreted polymeric mucins MUC5AC and MUC5B of the human lower airways

\subsection{Role of the major secreted polymeric mucins MUC5AC and MUC5B in mucociliary clearance}

The epithelial lining fluid of the human lower airways plays an essential protective role against particles and micro-organisms contained in inhaled air. It traps the microbes whilst the mucociliary escalator moves the fluid toward the oropharynx by the continuous beating of cilia (mucociliary clearance) [25]. The surface mucins generate an osmotic barrier that preserves the periciliary layer and co-ordinated ciliary motility, whereas secreted mucin proteins retain water and form viscoelastic gels. The physiological and immune functions of the major secreted polymeric mucins 
MUC5AC and MUC5B of the human lower airways in mucociliary clearance are summarised in Table 5.

8.2 The immune defence role of the major secreted polymeric mucins MUC5AC and MUC5B in human lower airways

Polymeric mucins MUC5AC and MUC5B have crucial roles in innate and adaptive immune defences of the human lower airways against viruses, bacteria, fungi and helminths. Mucins protect against epithelial adhesion and cytotoxicity of pathogens by interacting directly with infectious agents using more than 200 unique glycan structures [26]. The innate immune function of mucins also includes direct interactions with dendritic cells and mucin-secreting cells are sensors of environmental threats to the epithelial surface [13]. In addition, mucins may play an important role in suppressing the virulence of opportunistic pathogens and in promoting their coexistence in a stable microbiota [11].

9. The role of viruses and bacteria in modulating the synthesis/secretion of the major secreted polymeric mucins MUC5AC and MUC5B in the human lower airways

\subsection{Mucins and respiratory viruses}

Respiratory infection with viruses such as rhinoviruses (RVs), influenza $A(I A V)$ and respiratory syncytial virus (RSV) are common causes of COPD exacerbations and have many complex interactions with lower airway mucins. Viruses that enhance the synthesis/secretion of mucins in vitro are summarised in Table 4. 


\subsubsection{Rhinoviruses}

In human tracheal surface epithelial cells and submucosal gland cells obtained from patients 3-6 hours after death ( $n=83,39$ female, median age 60 \pm 5 years), rhinovirus (RV) 14 infection increased expression of MUC5AC and MUC5B $(p<0.05)$, MUC2, MUC3, and MUC6 $(p<0.01)$ mRNA in surface cells, compared with surface cells before infection. RV14 infection also increased expression of MUC5AC in surface cells after 24 hours by $\sim 40 \%$ more than before infection. Total mucin expression levels were also enhanced in the supernatants and lysates of these cells $(p<0.05)[27]$.

In submucosal gland cells, RV14 increased the mRNA expression of MUC5AC ( $p>0.01)$, MUC2, MUC5B and MUC7 ( $p>0.05)$ [27, 28]. MUC5AC production (both mRNA and protein) was also significantly increased in RV-infected human nasal epithelial cells (hNECs) compared with uninfected hNECs [29]. Differentiated primary human tracheobronchial epithelial cells, infected with either RV16 (a major group rhinovirus) or RV1A (a minor group RV) also show increased expression of both MUC5AC RNA and protein ( $p>0.05$ ) [30]. RV1A also induced mucin-secreting cell metaplasia and Muc5ac expression in mice, whereas RV16 did not have any effects, due to the differences in the expression of its receptor intercellular adhesion molecule 1 (ICAM-1) between human and mouse [30].

The Src-related $\mathrm{p44/42}$ mitogen-activated protein kinase pathway may also be associated with RVinduced mucin hypersecretion in human airways [27]. Furthermore, RV infection induced Foxa3 expression in mice in vivo and human airway epithelial cells in vitro, leading to increased mucinsecreting cell differentiation [31]. Viral replication is needed for RV-induced mucin expression, and this induction is dependent on Toll-like receptor (TLR) 3, suggesting the involvement of doublestranded RNA signaling [30]. 
COPD patients have increased susceptibility to RV and other infections [32]. Airway basal cells collected from tracheobronchial segments at the time of double lung transplantation from both COPD patients [n=8, 3 females, median age 57 years, median pack-years ( $p-y) 53$, median forced expiratory volume in 1 second $\left.\left(F E V_{1}\right) 22 \%\right]$ and never smoking subjects $(n=9,4$ females, median age 48 years) can be differentiated into mucociliary cells. Mucociliary-differentiated cells from COPD patients maintained for 15 days produced greater levels of MUC5AC $(p=0.015)$ and MUC5B $(p<0.001)$ mRNA expression than observed from cells from normal subjects [33]. MUC5AC and MUC5B gene expression $(p=0.008)$ was further increased in RV-infected cell cultures from COPD patients, compared to normal subjects. Alcian blue-periodic acid Schiff (AB-PAS) staining of paraffin-embedded cell cultures showed increased numbers of mucin-secreting cells $(p<0.001)$ in COPD patients compared to normal subjects [33]. After RV infection, COPD, but not normal cells, showed further increases $(p=0.008)$ in the numbers of goblet cells compared with respective shaminfected cell cultures [33].

These changes were associated with increased expression of FOXA3, a transcription factor expressed in mucin-secreting cells at baseline $(p<0.001)$ as well as after RV infection in COPD cells $(p=0.008)$. In contrast, the basal mRNA expression of FOXA2, a transcription factor that negatively regulates mucin-secreting cell differentiation, and FOXJ1, which promotes ciliated cell differentiation, were relatively lower in COPD compared to normal cell cultures [33].

\subsubsection{Influenza viruses}

Influenza A viruses (IAVs) interact with mucins and underlying ciliated cells. However, removal of the terminal sialic acids from mucins reduced virus binding to the mucus, confirming specific binding to sialylated receptors of the mucins [34]. Nevertheless, infection can occur in cells independently of sialic acids and involved the phosphatidylinositol 3-kinase (PI3K) pathway [35]. 
Since MUC1 is sialylated, it has the potential to bind to virions, reducing the ability to infect host cells and limiting infection [36].

Human lung epithelial cells are more susceptible to infection by pathogenic IAVs than low pathogenic viruses [37]. The 2009 H1N1 pandemic human IAV closely associates with MUC1 [36]. In human bronchial epithelial cell (HBEC) culture, infection with pathogenic seasonal H1N1 IAV resulted in the virus only being detected in MUC5AC-positive mucin-secreting cells whilst the infection significantly induced the expression of MUC1 mRNA $(p<0.05)$ [38]. In vivo Muc $1^{-1-}$ mice had heightened inflammatory responses to IAV compared to wild-type mice. Muc $1^{-1-}$ mice reached maximal viral titres earlier than wild-type mice, but also exhibited enhanced inflammatory responses to infection when viral titres were equivalent [36].

In vitro, $\mathrm{NCl}-\mathrm{H} 292$ cells infected with different IAV strains (seasonal and pandemic) and different subtypes (H3N2 and H1N1) induced MUC5AC gene expression after 16 hours [39]. Seasonal IAV strains were stronger inducers of MUC5AC expression compared to pandemic strains, and among these seasonal strains, the IAV A/Scotland/20/74 (H3N2) strain was the most efficient, with a 40fold increase over non-infected cells 24 hours after infection, compared with a maximal 300 -fold increase seen with phorbol ester stimulation [39]. The induction of MUC5AC correlated positively with viral matrix M2 gene expression, a direct index of viral replication [39]. Infection of $\mathrm{NCl}-\mathrm{H} 292$ cells increased the phosphorylation of extracellular signal-regulated kinases (ERK), with a first wave of activation starting as early as 5 minutes, and the second wave at 6 hours. The latter wave of activation being coincident with the first round of virus replication. Thus, the second wave of phosphorylated ERK was replication-dependent [39]. Furthermore, epidermal growth factor receptor (EGFR) was also shown to be involved in IAV-mediated MUC5AC mRNA expression and MUC5AC protein production [39].

In vitro, human alveolar adenocarcinoma cells (A549) infected with IAV H1N1, showed downregulation of two micro RNAs (miRNAs) (miR-17-3p and miR-221) targeting GALNT3 mRNA, that 
belongs to the family of uridine diphosphate (UDP)-GalNac transferases and catalyzes the Oglycosylation of mucin, leading to mucin production [38]. The induction of GALNT3 mRNA correlated with the release of viral genomic RNA into the culture supernatants. Both the viral genomic RNA and the viral titres were significantly reduced $(p<0.05)$ in Galnt $3^{-/-}$mice infected with IAV H1N1 [38].

IAV H1N1 infection of Muc5ac transgenic mice that overexpress lung Muc5ac mRNA by $\sim 20$-fold and Muc5ac protein $\sim 18-$ fold in the bronchoalveolar lavage (BAL) have significantly reduced lung viral loads $(p<0.001)$ compared with wild-type mice [40]. Conversely, C57/B16 mice infected with IAV H3N2 upregulate Muc5ac gene expression on days 3 and 4 after infection, which correlates with the peak of virus load [39].

\subsubsection{Respiratory syncytial virus}

Ex vivo respiratory syncytial virus (RSV) infection of well-differentiated primary HBECs increased mucus secretion and increased the numbers of mucin-secreting cells compared to sham infection [41]. Furthermore, in vitro RSV infection of A549 human lung epithelial cells elicited an 8-fold increase in the expression of MUC1 mRNA in a time-dependent manner, preceded by a 10-fold increase in TNFa production $(p<0.05)$ [42]. Another study showed that in vitro RSV infection of A549 cells induced significant increases of MUC8 gene expression compared to uninfected cells [43].

RSV induced significantly increased levels of MUC15, MUC20, MUC21 and MUC22 mRNA in A549 epithelial cells, compared with cells infected with human metapneumovirus, and increased levels of MUC4 and MUC16 $(p<0.05)$ compared with uninfected cells [43]. Increased levels of MUC5AC mRNA $(p<0.05)$ were also found in primary normal human bronchial epithelial cells 
(NHBECs) after 15 days of RSV infection [44], and increased Muc5ac gene expression is found in mice after RSV infection [45].

Recombinant RSV was able to infect p63+ basal cells both before and after the formation of a welldifferentiated epithelium. In the presence of ongoing RSV infection, the airway epithelium forms a monolayer and then differentiates, showing a significant reduction of ciliated cells and increased numbers of MUC5AC and MUC5B secretory cells [46].

\subsection{Mucin regulation by bacterial products}

Many respiratory bacterial infections such as Haemophilus influenzae, Streptococcus pneumoniae and Pseudomonas aeruginosa are common causes of COPD exacerbations and have many complex interactions with the mucins of the lower airways. Bacteria that up-regulate the synthesis/secretion of mucins in vitro are summarised in Table 4.

\subsubsection{H. influenzae and S. pneumoniae}

In vitro a lysate of non-typeable H. influenzae (NTHi) applied to A549 cells increased the early release of interleukin (IL)-8 and later production of MUC1 protein in a dose- and time-dependent manner through TLR2 [47]. The increased release of IL-8 was suppressed by MUC1 overexpression and enhanced by MUC1 knockdown. Notably, treatment with NTHi lysate-induced tumor necrosis factor (TNF)- $\alpha$ release following the up-regulation of MUC1, whereas MUC1 was completely inhibited by pre-treatment with soluble TNF- $\alpha$ receptor [47].

NTHi upregulated the nuclear factor kappa-light-chain-enhancer of activated B cells (NF-kB)dependent MUC2 mRNA transcription through the transforming growth factor (TGF)- $\beta$-Smad signaling pathway together with the TLR2-myeloid differentiation primary response 88 (MyD88)- 
TGF- $\beta$-activated kinase (TAK1)-NF-אB-inducing kinase (NIK)-IкB kinase (IKK) $\beta / \gamma$-inhibitor of kappa B (IкB) a pathway [48]. Pre-treatment of NTHi with a TGF- $\beta$ neutralizing antibody reduced the up-regulation of MUC2 transcription [48]. In addition, NTHi activates the p38 mitogen-activated protein kinase (MAPK) $\alpha$ - and $\beta$-mediated upregulation of MUC5AC transcription [49], but only after bacterial cell disruption [49]. This up-regulation of MUC5AC is driven by P6, a 16-kDa outer membrane lipoprotein that is well conserved in NTHi in a human lung epithelial cell line, in primary HBECs and in vivo in mouse lungs. This requires the TLR2-MyD88-interleukin-1 receptorassociated kinase 1 (IRAK1)-TNF receptor associated factor (TRAF6)-TAK1-dependent p38 MAPK-activating protein-1 (AP1) and IKK $\beta-I \kappa B \alpha-N F-\kappa B$ signalling pathways. MUC5AC mRNA expression is also induced in vitro by epidermal growth factor (EGF) that acts synergistically with NTHi, inducing the activation of p38 MAPK and ERK [50]. Combined challenged with NTHi and S. pneumoniae, synergistically induced MUC5AC expression in vitro via the TLR2/4-MyD88-TAK1 signalling cascade and activation of MKK3/6-p38 and ERK-MAPK pathways, but also by the activation of an AP-1 mechanism [51].

In vivo, weekly exposure to aerosolized NTHi lysate in mice did not increase gene transcription of the secreted or transmembrane mucins in the lower airways [52]. Combined exposure to both NTHi and cigarette smoke in vivo in mice induces significant increases in Muc5B $(p=0.041)$ and Muc5AC $(p=0.045)$ mRNA levels and increased numbers of periodic acid-Schiff (PAS) positive cells (indicative of mucin-secreting cell metaplasia) in large and small airways [53].

The activation of TGF- $\beta$ type II receptor-Smad3/4 signaling in vitro, leads to down-regulation of p38 MAPK activation by inducing MAPK phophatase-1, thereby acting as a negative regulator of MUC5AC induction [54]. Finally, activation of the PI3K-Akt pathway leads to the down-regulation of NTHi-induced MUC5AC transcription via negative cross-talk with the p38 MAPK pathway [49]. 


\subsubsection{P. aeruginosa}

$P$. aeruginosa engages the MUC1 ectodomain through its adhesin, flagellin $[55,56]$. In primary human alveolar macrophages isolated from the BAL of healthy subjects and human monocytic cell line (THP-1 cells), P. aeruginosa infection significantly increased MUC1 expression compared to uninfected cells [57]. Macrophages recognize this bacterium through TLR4 and the stimulation of the THP-1 cells with $P$. aeruginosa increased MUC1 protein levels 5.4-fold, whereas pre-treatment with the viral inhibitory peptide of TLR4 significantly reduced $P$. aeruginosa-induced MUC1 RNA levels down to 1.3-fold [58]. Furthermore, P. aeruginosa infection of human NCl-H292 airway epithelial cells increased MUC5AC mRNA and protein [59].

Infection with $P$. aeruginosa strain $\mathrm{K}$ in mice increased Muc1 expression in BAL compared to sham infection [55]. $\mathrm{Muc1}^{-1-}$ mice had reduced colonization of $P$. aeruginosa $(p<0.05)$ due to increased clearance by heightened early inflammatory responses to the infection, compared to wild-type mice [60]. Furthermore, $P$. aeruginosa strain K infection increased Muc5ac mRNA expression by 3-fold compared with flagellin-deficient mutant mice [59].

\section{Role of secreted mucins in the pathogenesis of stable COPD}

\subsection{Mucin gene SNPS and the risk of COPD development}

Most mucin genes contain a central region with tandem repeat sequences termed minisatellites (MS or variable number of tandem repeats $(\mathrm{VNTR})>10$ and $<100 \mathrm{bp}$ ) due to their length whereas microsatellites or short tandem repeats (STR) are $<10 \mathrm{bp}$. Each mucin gene has a VNTR, but there is little homology between the different mucins $[61,62]$. Although its effect on function is still unclear, the number of VNTR within many mucin genes has been associated with susceptibility to human diseases. 
The human MUC8 gene is located on chromosome $12 \mathrm{q} 24.3$ in a sub-telomeric chromosomal location and has 5 exons and 4 introns. It has 6 different (polymorphic) minisatellites, termed MUC8-MS1 to -MS6 that are meiotically stable and subject to Mendelian inheritance, each with 2 different alleles [61]. In a case-control study performed on COPD patients $\left(n=123, F E V_{1} / F V C\right.$ postbronchodilator $<0.70)$ and control subjects $(n=229,109$ female, average age 59.5 years) there was a significant association between the presence of a MUC8-MS5 minisatellite polymorphism, represented by the presence of short alleles (2/2 repeats), and the risk of COPD [63].

The MUC5B gene common promoter variant rs35705950 is the strongest genetic risk factor for idiopathic pulmonary fibrosis (IPF), both in the sporadic and familial setting, and may also be associated with a less rapid disease course [18, 64]. MUC5B rs35705950 T-carrier status is selectively associated with increased protein expression of MUC5B only in IPF patients. The MUC5B SNP rs35705950 disrupts a CpG motif in the promoter region. 32bp downstream of the rs35705950 SNP is a highly conserved FOXA2 binding motif. This region is hypermethylated in IPF and is associated with increased expression of MUC5B in lung tissue. This hypermethylation may result in increased occupancy of the FOXA2 binding motif leading to increased MUC5B expression (Caramori G et al 2019 under revision).

Genotyping of the MUC5B promoter polymorphism rs35705950 was performed in non-Hispanic whites ( $n=454,253$ males, average age 66 years, 152 current smokers, average 49.5 p-y, FEV 1 $79 \%$ of predicted) within the COPDGene cohort with interstitial features defined by the presence of interstitial or emphysematous features in $>10 \%$ of their lung volume. This reported frequencies of 0.7\% for MUC5B TT homozygotes (the minor allele), $20.7 \%$ for GT heterozygotes and $76.8 \%$ for GG homozygotes (the major allele) [65]. MUC5B expression in lung tissue of COPD patients with interstitial features did not vary between homozygotes and heterozygotes [18, 66]. However, rs 35705950 was associated with a $61 \%$ lower risk of prospectively reported exacerbations, a longer time-to-first event of acute respiratory disease and $40 \%$ fewer events of acute respiratory 
disease [65]. These subjects also had a lower risk of severe exacerbations that required an emergency room visit or hospitalisation compared to those without the polymorphism [65].

Clearly more studies are needed in this area using larger populations of deeply phenotyped COPD patients.

\subsection{Sputum and mucins in stable COPD}

COPD patients often have sputum production [67], and many meet the criteria for the diagnosis of chronic bronchitis, defined as consecutive months of cough and sputum production over a period of 2 years. The presence of chronic bronchitis is a predictor of worse overall mortality, COPDrelated death, increased exacerbation frequency, accelerated decline in lung function and worsening quality of life [68-70]. COPD patients who are persistent sputum producers defined as patients bringing up phlegm for four or more days of the week $(n=26)$ have increased rates of bacterial colonization and pneumonia compared to non-persistent sputum producers who do not produce phlegm except during an exacerbation $(n=26)$. Indeed, bacteria were detected more frequently in persistent sputum producers (60\% of total), compared to non-persistent sputum producer (only 1 patient, equal to the $7 \%$ of the total). The most frequent microorganisms isolated in persistent sputum producers were $H$. influenzae $(n=7)$ and S. pneumoniae $(n=3) . H$. influenzae was the most isolated bacteria in the sputum of non-persistent sputum producer patient [71].

Induced sputum and bronchoabsorption samples were collected from patients with chronic bronchitis and COPD ( $n=68)$, control smokers with normal lung function $(n=34)$ and non-smoking subjects $(n=29)$ [72]. Sputum and bronchoabsorption sample composition was different between chronic bronchitis and COPD patients with an increased ( $\sim 3$ fold) amounts of solids compared with both control groups [72]. In patients with chronic bronchitis and COPD there were increased amounts of total sputum mucin compared to control smokers with normal lung function but not in 
non-smoking subjects as determined using size exclusion chromatography coupled on-line to multi angle laser light scattering (SEC/MALLS) [72]. Total mucin was not measured in the bronchoabsorption samples [72]. Spontaneous sputum was collected in a subset of six patients with chronic bronchitis and COPD and sputum partial osmotic pressure correlated directly with sputum percentage of solids when measured with a custom-designed direct-membrane colloid osmometer incorporating a 10-kD membrane [72]. In vivo muco-ciliary clearance measured by the gamma scintigraphy correlated negatively with the percentage of solids in bronchoabsorption samples in a distinct subset of 43 patients with chronic bronchitis and COPD [72].

In another smaller study spontaneous/induced sputum was collected from stable COPD patients $(n=15)$ and from a control group of smokers with normal lung function $(n=17)$ [73]. Samples were separated into two phases: "gel", for samples which were able to support their own weight when separated by tweezers and "sol" those were more liquid. There were no significant changes in sputum sample mucin concentrations between COPD patients and controls [73]. Quantisation of polymeric MUC5AC and MUC5B was performed using a combination of gel-filtration chromatography and isopycnic density-gradient centrifugation and quantitative Western blotting. MUC5AC and MUC5B proteins were present in all sputum samples from COPD patients and controls. MUC2 was present in 2 samples from COPD patients and 1 sample from controls but only at very low levels. MUC5AC protein concentration (relative to gel weight) was significantly increased in the gel phase of sputum samples from controls but not COPD patients. In COPD patients, sputum MUC5B was present in different glycoforms with a predominance of low-charge glycoforms. The MUC5B/MUC5AC ratio in the gel phase of the sputum correlated inversely with post-bronchodilator (BD) $\mathrm{FEV}_{1}$.

The Subpopulations and Intermediate Outcome Measures in COPD Study (SPIROMICS), is an observational study that investigated a large cohort of COPD patients $(n=2,981$, current or former smokers with a smoking history of more than 20 p-y [74]. SPIROMICS collected induced sputum 
from COPD patients with an $\mathrm{FEV}_{1}>35 \%$ of predicted $(\mathrm{n}=917)$ and control never-smoking subjects ( $n=69$ ). COPD patients were divided into different disease stages: (i) GOLD stage $0, n=303$; (ii) GOLD stage 1, n=165; (iii) GOLD stage 2 and (iv) GOLD stage 3, n=85. In addition, 113 "COPD" patients had a self-reported diagnosis of bronchial asthma compared to no subjects in the control group.

Induced sputum total mucin determined using SEC/MALLS was significantly increased in COPD GOLD stage 2 patients compared to stage 0 and 1 but not control non-smokers. Sputum total mucin was increased in COPD GOLD stage 3 patients compared to non-smoking control subjects. Sputum total mucin was also increased in all smokers (current of former) compared to control nonsmokers and in smokers (current or formers) with chronic bronchitis $(n=434)$ compared to smokers (current or formers) without chronic bronchitis $(n=397)$. Induced sputum total mucin concentration was associated with the prospective annualized exacerbation rate during the study (zero exacerbations per year $n=596$, more than zero exacerbations per year $n=262$, and $\geq 2$ exacerbations per year $n=36$ ). Induced sputum total mucin concentration was increased in all patients with exacerbations compared to patients without exacerbations and correlated significantly with the presence of chronic bronchitis $(\mathrm{ROC}=0.79)$.

MUC5B and MUC5AC within induced sputum were analysed using mass spectrometry in a subset of COPD patients (mild-to moderate $n=59$ and severe $n=28$ ) and in control groups of smokers (current or formers) with normal lung function $(n=42)$ and never-smoking subjects $(n=19)$. The concentration of MUC5B within induced sputum was on average 10 times greater compared with MUC5AC across all groups. The MUC5B concentration was significantly increased ( 3 fold) in COPD stage 3 patients only compared to non-smokers, but not compared to control smokers with normal lung function and mild-to-moderate COPD patients. The concentration of MUC5AC in induced sputum was significantly increased ( 10 times) in all (mild-to-moderate and severe) COPD patients and control smokers with normal lung function compared to non-smoking controls, but 
there were no significant differences between smokers with or without COPD. MUC5AC was also significantly increased in all current smokers compared to non-smoking control subjects. Overall, MUC5AC and MUC5B concentrations in induced sputum were significantly increased in COPD patients with chronic bronchitis compared to those without chronic bronchitis regardless of the presence of pulmonary emphysema.

\subsection{Bronchial tissues and mucins in stable COPD}

AB-PAS and MUC5AC and MUC5B immunohistochemistry was quantified in bronchial rings obtained from COPD patients $(n=20)$ control smokers with normal lung function $(n=20)$ and nonsmoking subjects $(n=10)$ [75]. The area occupied by MUC5AC+ cells in bronchial submucosal glands was increased in COPD $(20 \%, 5.5-31.7 \%$, gland area) compared with smokers with normal lung function $(9.5 \%, 2.5-17.5 \%)$ and non-smoking subjects $(2 \%, 0.4-6.2 \%)$. The area occupied by MUC5AC+ cells in the bronchial surface epithelium was also increased in smokers (with/without COPD, $73.5 \%$, 25-92\%, epithelial area) compared with non-smoking subjects (15\%, $2.7-32 \%)$ despite no difference in gland size (Reid index) [76] between groups. Alcian blue (AB)-PAS staining and MUC5B expression were also not significantly different between groups.

Previous reports have indicated conflicting results regarding MUC5AC and MUC5B expression in COPD. For example, MUC5AC expression correlated with the degree of airflow obstruction, and MUC5AC and MUC5B expression correlated with p-y. Furthermore, increased MUC5AC expression was reported in the bronchial surface epithelium from smokers (with or without COPD) [77]. In addition, there was a significant correlation between MUC5AC expression and p-y [75] highlighting the potential of tobacco smoking and its components such as acrolein and oxidants to induce MUC5AC synthesis in bronchial epithelial cells in an NF-кB-dependent process [14]. 
These data are in contrast with a more recent smaller study comparing moderate-to-severe COPD $(n=15)$, smokers with normal lung function $(n=12)$ and non-smokers $(n=11)$ [78]. Six endobronchial mucosal biopsies per subject were obtained by bronchoscopy. Smokers with normal lung function had a significantly increased mucin-secreting cell density and mucin volume density compared to smokers and COPD patients. All current smokers $(n=19)$ compared with all non-smoking and former smoking subjects $(n=19)$ had a significantly increased mucin-secreting cell density and mucin volume density. A significant correlation between p-y and mucin-secreting cell density was shown. However, no significant difference in mucin-secreting cell density and mucin volume density was observed in current smoker COPD patients compared to ex-smokers with COPD [78].

Chronic bronchitis patients ( $n=21,19$ COPD patients and 2 smokers with normal lung function) had increased mucin-secreting cell density, but not mucin volume density compared to patients without chronic bronchitis $(n=26)$. The same results were found comparing COPD patients with and without chronic bronchitis, with increased mucin-secreting cell density in chronic bronchitis COPD patients. Multivariate analysis indicated that current smoking and chronic bronchitis are significant predictors of mucin-secreting cell density.

Fresh lung tissues collected from COPD patients and from smokers with normal lung function (number and clinical data not specified) who underwent lung resection surgery for suspected or confirmed lung cancer, as distal from tumour as possible were examined for mucus expression [73]. Sections from each lung sample were stained with haematoxylin and eosin (H\&E) and ABPAS and immunostained for MUC5AC and MUC5B. Tissues from COPD patients and smokers with normal lungs showed intense staining of cells in the epithelial surface and submucosal glands, with increased MUC5AC in the epithelial surface cells and increased MUC5B in submucosal glands cells, but no specific count data was provided. Minor staining of MUC5AC was observed in the submucosal glands in both groups whilst MUC5B staining was present in the surface epithelium from COPD patients but not smokers with normal lung. 
Primary HBECs were obtained from bronchial tissues harvested from lung transplant COPD patient recipients $(n=16)$, as well as from control non-COPD subjects $(n=17)$ [79]. Primary HBECs were differentiated in vitro at ALI culture with or without IL-13. In the presence of IL-13, mucinsecreting cell differentiation, MUC5AC (mRNA and protein), SAM pointed domain-containing Ets transcription factor (SPDEF) and anterior gradient protein 2 homolog (AGR2) expression were all significantly increased in HBECs from COPD patients compared to controls, but FOXA2 expression was significantly reduced. In the absence of IL-13, FOXA2 expression was unchanged. Interestingly, a proteomic study has been undertaken examining brush biopsies obtained from ecigarette users (vapers, $n=10$ ) compared to controls that were smokers with normal lung function $(n=15)$ and non-smoking subjects $(n=18)$ [80]. MUC5AC protein levels were increased both in vapers and control smokers with normal lung function compared to control non-smoking subjects, whereas there was a non-significant trend towards increased MUC4 protein levels only in subjects who vaped.

\subsection{Peripheral lung tissues and mucins in stable COPD}

Airflow obstruction in COPD is caused by small (peripheral) airway lesions and their intraluminal levels of mucus correlates with the degree of COPD severity [81]. The point of greatest airflow obstruction in COPD is at the level of the intraparenchymal airways where the diameter is less than $3 \mathrm{~mm}$ (small airways) [82].

Lung tissue samples were obtained from COPD patients $(n=101)$ with severe (GOLD stage 3 ) and very severe (GOLD stage 4) after lung volume reduction surgery for advanced pulmonary emphysema [83]. The control group were lung tissue samples obtained from milder COPD patients $(n=101)($ GOLD stages $0-2)$ none of whom underwent on lung volume reduction surgery. Digital images of the airway histology were captured. The size of small conducting airways was estimated 
by measuring the length of the basement membrane and determining lumen area in both the partially collapsed state where the basement membrane was folded, and in a simulated fully expanded state calculated by subtracting the area of the epithelium from the area of a circle with a perimeter equal to the airway basement membrane length. The severity of luminal occlusion was expressed by determining the fraction of lumen areas occluded by inflammatory exudate containing mucus. The thickness of the entire airway wall as well as its epithelial, lamina propria, muscle, and adventitial compartments were determined by dividing their measured areas by the length of the airway basement membrane. The percentage of airways containing a collection of lymphocytes consistent with the formation of a lymphoid follicle was also defined. The COPD patients were divided in four quartiles according to the percentage of occlusion of the fully expanded lumen of their small airways and the median follow-up time was 79 months. As expected, the median survival time was shortest in the quartile of COPD patients with the most severe luminal occlusion (48 months). The median survival time was longest in patients with the least luminal occlusion (>92 months). Patients in the quartile with the highest luminal content had a 3-fold greater risk of mortality compared to the quartile of patients with the lowest luminal content. The severity of lumen occlusion was not associated with the diagnosis of chronic bronchitis, airway wall thickening, the percentage of the airways containing lymphoid follicles or predicted survival after lung volume reduction surgery.

In another study, lung tissue samples were obtained from COPD [n=9, 9 male, average $F E V_{1}$ of $69 \pm 5 \%, \mathrm{FEV}_{1 /}$ forced vital capacity (FVC) 62 \pm 2 ] patients that underwent lung resection for a solitary peripheral carcinoma, avoiding areas involved by tumour. Samples were also obtained from ageand pack year-matched smokers with normal lung function $\left(n=6,2\right.$ females, mean $F E V_{1}$ of $79 \pm 2 \%$, FEV $1 / F V C 97 \pm 4$ ) and non-smokers ( $n=6,6$ male, average $F E V_{1}$ of $\left.103 \pm 5 \%, F E V_{1} F V C 81 \pm 3\right)[84]$ Two sections from each subject were stained with AB-PAS. In lung tissue from COPD patients there was significantly increased intraluminal staining (neutral mucins). 
MUC5B immunostaining of the luminal mucus was significantly more frequent in lung tissue from COPD patients ( $n=6$ of 9 ), compared with smokers with normal lung function $(n=1$ of 6$)$ and with non-smokers $(n=1$ of 6$)$. MUC5AC was increased in the bronchiolar epithelium of the small airways from COPD patients compared with smokers with normal lung function and with non-smokers. These changes may contribute to the pathogenesis of small airway obstruction and increased risk of pneumonia of COPD patients.

Lung samples from COPD patients $(n=14)$ who underwent pulmonary nodule resection were compared with lung samples from smokers with normal lung function $(n=14)$ and with non-smokers $(n=14)$ [85]. Cigarette smoke history was not significantly different between the COPD patients and smokers with normal lung function. The number of smoking years was significantly higher in COPD patients than in smokers with normal lung function. $\mathrm{FEV}_{1}(\%$ predicted $)$ and $\mathrm{FEV}_{1} / \mathrm{FVC}$ ratio were significantly lower in COPD patients than in smokers with normal lung function and non-smoker subjects. To determine the inflammatory response and mucus secretion in the lung specimens, H\&E was used to stain areas with inflammation, and AB-PAS was used to stain mucin glycoproteins. Lung tissue was then stained with mouse anti-human MUC5AC primary antibodies. H\&E staining of lung tissues from COPD patients showed inflammatory cell infiltration and destruction of epithelial integrity whereas the airway epithelial cells in non-smokers had less inflammatory cell infiltration and were well-arranged, with complete basement membranes. The pathological features of the cells of lung tissue in smokers with normal lung function were inbetween those of non-smokers and COPD patients. Lung tissue from COPD patients possessed $54 \%$ AB-PAS-positive areas compared with $21.3 \%$ in lung tissue from smokers with normal lung function and $5 \%$ in the lung tissue from non-smokers. The average optical density was used to determinate the expression of MUC5AC. In lung tissue from COPD patients MUC5AC was increased compared to smokers without with normal lung function. In tissue from smokers without with normal lung function MUC5AC was increased compared to non-smokers. 
In another study, BAL obtained from stable COPD patients $\left(n=42\right.$, mean $F E V_{1}$ post-bronchodilator $65 \%$ of predicted) was compared to that from smokers with normal lung function ( $n=12$, mean $\mathrm{FEV}_{1}$ post-bronchodilator $106 \%$ of predicted) and from never smokers $\left(\mathrm{n}=5\right.$, mean $F E V_{1}$ postbronchodilator $107 \%$ of predicted) [86]. MUC5AC and MUC5B levels were increased in BAL from stable COPD patients compared to that from smokers with normal lung function and non-smokers. The ratio of MUC5AC:MUC5B increased from 0.3 in non-smokers to closer to 1.5 in smokers with normal lung function and 0.5 in stable COPD patients.

BAL was also collected from patients with stable severe COPD $(n=45$, mean FEV 1 postbronchodilator $41 \pm 10 \%$ of predicted) [87]. Patients were divided into two groups: "colonized" $(n=14)$ or "non-colonized" $(n=31)$. The most common pathogens collected from "colonized" patients were $H$. influenzae $(n=8)$, S. pneumoniae $(n=2)$, Moraxella catarrhalis $(n=2)$, Neisseria meningitidis $(n=1)$ and Escherichia coli $(n=1)$. COPD patients with bacterial colonization had increase frequency of exacerbation.

In BAL from stable COPD patients, MUC2 had the highest levels of all mucins (mean $8.1 \pm 4.4$ $\mathrm{ng} / \mathrm{mL}$ ). MUC5AC levels were $80.3 \pm 11.2 \mathrm{pg} / \mathrm{mL}$ and MUC5BC levels were $6.4 \pm 4.0 \mathrm{pg} / \mathrm{mL}$ ). In BAL from stable colonised patients MUC2 levels were reduced compared to stable uncolonised patients $(6.36 \pm 1.3$ vs. $8.96 \pm 4.9 \mathrm{ng} / \mathrm{ml})$. MUC5AC $(80.3 \pm 4.3$ vs. $80.36 \pm 13.0 \mathrm{pg} / \mathrm{ml})$ and MUC5B $(8.86 \pm 10.8$ vs. $4.26 \pm 3.0 \mathrm{ng} / \mathrm{ml}$ ) levels were not significantly different between colonised and uncolonised groups.

\section{Role of secreted mucins in the pathogenesis of COPD exacerbations}

Unfortunately, there are only a few studies that have examined the potential contributions of mucins to the pathogenesis of COPD exacerbations. 


\subsection{Blood mucins in COPD exacerbations}

Serum levels of cancer antigen (CA)-125 (an epitope of MUC16) were measured in a cohort of COPD patients, hospitalized for COPD exacerbation and control subjects $(n=40)$ [88]. COPD patients were classified into 2 groups high CA-125 ( $\geq 35 \mathrm{U} / \mathrm{mL})$ and normal CA-125 (<35 U/mL). Serum CA-125 levels were significantly increased in COPD patients at stages 3 and 4 , but not stage 2, compared to control subjects (median $33.94 \mathrm{U} / \mathrm{mL}$ vs $9.76 \mathrm{U} / \mathrm{mL}$ ). In COPD patients, CA125 levels correlated with $\mathrm{FEV}_{1} / \mathrm{FVC}$, disease severity, systolic pulmonary artery pressure (sPAP), tricuspid annular plane systolic excursion (TAPSE), tricuspid lateral annulus S velocity and with severity of tricuspid regurgitation and with right atrial size. Increased serum CA-125 levels identified the presence of associated of right ventricular failure with a sensitivity of $89.5 \%$ and specificity of $85.7 \%$.

In another study, blood from COPD patients $(n=52)$ hospitalized during COPD exacerbation was collected on the admission day, prior to the administration of antibiotics or any other medication. There was no control group [89]. CA125 was measured by chemiluminescence and the serum reference range of CA-125 was $<35 \mathrm{KU} / \mathrm{L}$. GOLD stage D COPD patients had increased levels of CA-125 compared to GOLD stage C patients $(53.8 \pm 4.6 \mathrm{KU} / \mathrm{L}$ versus $14.1 \pm 5.4 \mathrm{KU} / \mathrm{L})$.

\subsection{Sputum mucins in COPD exacerbations}

Sputum from COPD patients $(n=9)$ was collected at the onset of a COPD exacerbation, defined as increased dyspnoea and cough, increased sputum volume and change in sputum colour (to be included in the study at least 2 symptoms with an onset within 7 days was required) [90]. All patients were treated with oral glucocorticoids for 10 days, and inhalation therapy with long-acting antimuscarinic antagonist and short- and long-acting beta2-agonist. The control group was represented by pulmonary secretions collected by endotracheal tubes of subjects who had no lung 
disease (no clinical data provided). All patients were followed up 5-6 weeks after the onset of exacerbation and at the end another sputum sample was collected. Sputum samples from COPD patients during exacerbation had a 5-fold increased MUC5AC and a 2-fold increased MUC5B levels. Five- 6 weeks later, at the end of the exacerbation, sputum MUC5AC levels remained $\sim 3-$ fold higher compared to pulmonary secretions from non-COPD controls but were 2-fold lower than at the start of the exacerbation. At the same time, sputum MUC5B levels in COPD patients decreased back to levels seen in controls. COPD sputum was also incubated with different concentrations ( $0-40 \%)$ of cigarette smoke condensate for 0,24 and 36 hours. A dose-dependent inhibition of mucin degradation was observed compared to vehicle exposure although MUC5AC and MUC5B were degraded significantly after 24-36 hours.

Induced sputum from COPD ( $n=78)$ patients was collected during COPD exacerbation (defined by a background diagnosis of COPD, according to GOLD recommendations, and at least two major symptoms of dyspnea, increased sputum purulence or production, or one major and one minor symptom of nasal discharge/congestion, wheeze, sore throat or cough, for at least two consecutive days) [91]. Induced sputum was also collected from each patient in the remission phase, considered to be when symptoms were alleviated after standard medical treatment for at least 5 days. Sputum MUC1 levels were increased in COPD patients during exacerbation compared to the remission phase.

\section{Pharmacological modulation of the mucin synthesis/secretion/structure in the lower airways of COPD patients}

Although the symptoms of chronic bronchitis are associated with increased morbidity and mortality in the COPD patients, the pathophysiological and clinical significance of mucin changes during the stable phase and exacerbations and the therapeutic value of drugs that act on these mucins 
(termed mucoactive drugs or mucin synthesis/secretion/structure modulators) is controversial, particularly in light of recent studies (reviewed above) showing a fundamental role of many mucins in innate immune responses of the human lower airways.

We review here the in vitro and in vivo (both animal and human studies) effects of commercially available drugs and new compounds in preclinical or early clinical development that may influence the amount and/or biochemical structure of mucins in the lower airways of COPD patients. We also review clinical studies showing the effects of these drugs/compounds in the treatment of COPD patients in stable phase and/or during exacerbations. We did not consider studies performed in stable COPD patients with these drugs/compounds if:

a) A placebo control group was absent.

b) Their duration was less than 12 months, because of the well-established seasonality of the COPD exacerbations.

c) Did not provide sufficient clinical details (e. g., age, smoking history, pre- and post-BD FEV1, FVC and their ratios) to have a likely diagnosis of COPD according to current standards.

12.1. Effects of the drugs available for the treatment of COPD patients on mucin synthesis/secretion/structure

It is noteworthy that there is a lack of controlled clinical trials investigating the effects of commercially available drugs for the treatment of COPD patients on mucin synthesis/secretion/structure in the lower airways.

\subsubsection{Inhaled and/or systemic glucocorticoids}


The effects of glucocorticoids on MUC5AC expression are still controversial. In vitro their effects appear cell-type dependent. Fluticasone propionate significantly reduced MUC5AC protein levels in H292 human lung mucoepidermoid carcinoma cells [92]. In contrast, treatment with dexamethasone did not significantly change steady-state MUC5AC mRNA levels in cultured HBECs obtained from nasal polyps [93] and even enhanced both MUC5AC protein and mRNA levels in cultured normal HBECs [94].

In HBECs grown at air-liquid interface (ALI), dexamethasone did not reduce mucin-secreting cell differentiation when cultures are co-stimulated with IL-13 [94]. Recent transcriptomic studies [95] identified genes upregulated in human bronchial brushings and endobronchial biopsies following budesonide treatment. Many genes associated with mucin-secreting cell differentiation such as ErbB4, runt-related transcription factor 2 (RUNX2), as well as janus kinases (JAK)/ signal transducer and activator of transcription proteins (STAT) and PI3K/AKT signaling pathways, were upregulated in response to budesonide. In contrast, a small pilot study evaluated patients with persistent untreated non-allergic rhinitis (NAR, $n=12$, mean age $39.5 \pm 4$ years, all non-smokers) compared with patients with persistent NAR $(n=12$, mean age $48 \pm 4$ years, all non-smokers $)$ under regular treatment with nasal fluticasone furoate for at least 20 days and compared to normal control subjects ( $n=12$, mean age $32.5 \pm 3$ years, all non-smokers) [96]. No patients or control subjects had been treated in the previous 60 days with systemic and/or nasal glucocorticoids, antihistamine 1 receptor drugs, anti-leukotrienes, methylxanthines, or any kind of immunosuppressive drugs, mucolytics/antioxidants drugs by systemic or local routes. Each subject went underwent a single nasal scraping performed under direct visual inspection and defined the ratio between ciliated and mucin-secreting cells, usually in favour of ciliated cells [97]. Immunocytochemical staining for MUC5AC was performed [96] Nasal scrapes obtained from patients with untreated NAR showed different total numbers of nasal epithelial cells compared with scrapes from both normal subjects and NAR patients treated with nasal fluticasone furoate $(92.3 \pm 17.2$ vs $413.8 \pm 2.8$ 
vs $407.8 \pm 62.6$, respectively). Total nasal epithelial cell numbers were similar between NAR patients treated with nasal fluticasone furoate and normal subjects. In nasal scrapes from untreated NAR patients, the mucin-secreting cell percentage was significantly increased compared to normal subjects and to NAR patients treated with nasal fluticasone furoate $(22.6 \pm 5.0$ vs $4.4 \pm 0.6$ vs $3.0 \pm 0.4 \%$, respectively). The numbers of MUC5AC+ nasal epithelial cells over the total number of nasal epithelial cells was increased in scrapes from untreated NAR patients compared to control subjects $(41.8 \pm 6.4$ vs $22.3 \pm 4.8 \%)$.

In vivo, inhaled fluticasone propionate treatment of rhinovirus infection in mice, increased MUC5AC and MUC5B proteins in BAL at day 7 post-infection $[98,99]$. Dexamethasone upregulated MUC5AC expression, and reduced MUC5AC production and mucin-secreting cell differentiation in animal models but had no effect on MUC5AC mRNA $[100,101]$.

The effect of glucocorticoid therapy on the airway histology was determined in lung tissue samples obtained from COPD patients ( $n=94)$ with severe (GOLD stage 3 ) and very severe (GOLD stage 4) after lung volume reduction surgery for severe pulmonary emphysema, by comparing the histology of COPD patients not on therapy $(n=16)$ with lung tissue samples from COPD patients who received inhaled glucocorticoid therapy only $(n=45)$, and with lung tissue samples from COPD patients who received oral glucocorticoid therapy with or without inhaled glucocorticoid therapy $(n=33)$ up until the time of their lung volume reduction surgery [83]. The size of the small conducting airways and severity of the luminal occlusion were estimated. COPD patients treated with oral glucocorticoid with or without inhaled glucocorticoid therapy were slightly less dyspnoeic but had a shorter 6-minute-walk, and reduced quality of life compared with treatment with inhaled glucocorticoid only and with COPD patients who did not receive glucocorticoid therapy. Neither oral glucocorticoid therapy nor inhaled glucocorticoid therapy affected luminal content or airway wall thickness. There was a negative association between glucocorticoid therapy and the percentage of airways containing lymphoid follicles, with pair wise comparisons showing 
differences between patients that received oral glucocorticoid with or without inhaled glucocorticoid therapy and those who did not receive therapy.

\subsubsection{Inhaled anti-muscarinics}

Differentiation of mucin-secreting human airway epithelial cells grown at ALI by IL-13 can be prevented and reversed by anti-muscarinic (tiotropium) treatment, suggesting a direct role for nonneuronal acetylcholine $[102,103]$. Studies of animal models confirm this contention and show reduced mucin-secreting cell differentiation after anticholinergic treatment in COPD models [103]. In patients with chronic bronchitis and/or stable COPD it is debateable whether ipratropium, oxitropium and tiotropium significantly improve mucociliary clearance [104, 105]. Hemicholinium-3, a potent and selective choline uptake blocker, has been demonstrated to reduce MUC5AC production in H292 human pulmonary mucoepidermoid carcinoma cells stimulated with cigarette smoke [92].

\subsubsection{Inhaled beta2-agonists}

Inhaled short-acting beta2 agonists promote mucus clearance by increasing airway luminal diameter; ciliary beat frequency by enhancing intracellular cAMP levels and mucus hydration by stimulating airway $\mathrm{Cl}^{-}$secretion via activation of cystic fibrosis transmembrane conductance regulator (CFTR) [106]. Together, this results in decreased mucus viscosity and allows easier transport by airway cilia. Inhaled long-acting beta2-agonists also stimulated mucociliary clearance $[107,108]$ which may reflect the in vitro ability of salmeterol to stimulate ciliary beat frequency [109]. In addition, formoterol significantly improves mucociliary clearance compared to placebo. 
Finally, in animal models, short-term administration of beta2-agonists is associated with upregulation of mucociliary clearance $[110,111]$.

\subsubsection{Phosphodiesterase-4 inhibitors}

EGF increases MUC5AC gene expression and protein production in A549 cells [112]. Roflumilast is a phosphodiesterase- 4 inhibitor that did not change basal MUC5AC expression but dosedependently prevented EGF-enhanced MUC5AC mRNA and protein production. In human lung tissue from COPD patients $(n=6)$ who underwent surgery for lung carcinoma, roflumilast prevented EGF-induced MUC5AC mRNA and protein expression.

Well-differentiated HBECs infected with RSV and maintained until day 15 post-infection exhibit increased numbers of mucin-secreting cells and MUC5AC expression and a suppression of their antioxidant capacity [44]. All these RSV-induced changes were prevented by treatment with roflumilast.

TAS-203 is an oral PDE4 inhibitor [113] that prevents EGF-induced intracellular and extracellular MUC5AC expression in NCI-H292 cells [114]. TAS-203, but not roflumilast, prevented cigarette smoking-enhanced BAL Muc5ac expression in an animal model of COPD [114].

\subsubsection{Macrolides}

Macrolides are antibiotics that interfere with bacterial protein synthesis but may also have complex anti-inflammatory effects including modulation of mucin synthesis [115]. Macrolides induce the release of small amounts of mucin from isolated airway submucosal glands via partial agonism of muscarinic receptors, but conversely suppress stimulated mucin release by interfering with intracellular calcium handling [116]. Clarithromycin treatment of IL-13-stimulated HBECs drastically 
reduced the levels of SPDEF, mucin-secreting cell specific calcium-activated chloride channel regulator 1 (CLCA1), ERK1/2 phosphorylation and overall mucin-secreting cell number [117]. MUC5AC secretion from the human $\mathrm{NCl}-\mathrm{H} 292$ cell line was decreased with both chloramphenicol and erythromycin [118]. MUC5AC mRNA expression was also reduced, most likely via inhibition of IL-13 signalling pathways [119].

\section{Mucins synthesis/secretion/structure modulators already on the market for the}

\section{treatment of COPD patients}

Despite many drugs/compounds being developed to modulate mucin synthesis/secretion/structure the mechanisms of action for most of these drugs are still not fully characterized and these drugs/compounds may also have a plethora of additional pharmacological effects including actions on inflammatory and oxidant pathways. Thus, the beneficial clinical effects produced by these drugs/compounds may not reflect their direct action on mucins.

The old classification of these drugs/compounds into "mucolytics", "mucoregulators" "expectorants" has little value [120]. Mucolytics are defined according to (i) the presence of a free sulfhydryl group capable of dissociating the disulphide bonds within mucins that contribute to increased mucus viscosity and the formation of a gel or (ii) proteolytic enzymes such as DNAses, that dissolve the mucin gel through other mechanisms and thus, collectively potentially reducing the viscosity of the mucus itself. In contrast, mucoregulators do not contain free sulfhydryl groups but may modulate mucin synthesis/secretion and expectorants increase the production of mucus to such an extent that it can be expectorated by coughing and/or are irritating and cause coughing which in turn helps to eliminate mucins [120]. 


\subsection{Ambroxol}

Ambroxol is a metabolite of the bromexine [121]. In IL-13-stimulated differentiated HBECs treated in vitro with ambroxol, there was a significant reduction in MUC5AC expression but no effect on antioxidant capacity [122]. In addition, pre-treatment of human lung epithelial cells with ambroxol inhibited cigarette smoke-induced MUC5AC expression [123].

In an animal model of lipopolysaccharide (LPS)-induced mucus hypersecretion, an inhaled solution of ambroxol inhibited BAL Muc5ac expression, enhanced the function of mucociliary clearance and promoted sputum excretion. Ambroxol also significantly reduced the number of LPS-induced inflammatory cells [124]. In an acute cigarette smoke-exposure model (10 cigarettes per day for 4 days), pre-exposure to aerosolised inhaled ambroxol reduced lung Muc5ac mRNA levels and improved mucociliary clearance [123].

There is a complete absence of long-term, good quality controlled clinical trials of ambroxol in the prevention of COPD exacerbations.

\subsection{Carbocysteine}

Carbocysteine (S-carboximetilcysteine) is a mucin synthesis/secretion/structure modulator compound derived from cysteine with a blocked thiol group that is unable to break disulfide bonds [125]. Carbocysteine does not reduce the viscosity of canine tracheal mucus [126] or of human nasal mucus secretions [127]. However, in a murine model of COPD exposed subacutely to cigarette smoke, carbocysteine inhibits hypersecretion of tracheal mucus [128].

\subsubsection{Controlled clinical trials of carbocysteine in COPD exacerbations}


A 1-year randomised, double-blind, placebo-controlled trial from 22 centres in China of COPD patients during exacerbation $(n=709)$ has been reported. Exacerbations were defined as at least 2-day persistence of at least two major symptoms (worsening dyspnoea and an increase in sputum purulence, volume, or both) or of any single major symptom plus more than one minor symptom (upper airway infection, unexplained fever, and increased wheezing). There was a reduced number of exacerbations (325 versus 439 ) in patients randomly assigned to receive carbocysteine $1500 \mathrm{mg}(\mathrm{n}=353)$ compared to placebo $(n=354)$ daily for a year with an exacerbation risk ratio of $0.75(p=0.004)[129]$. Analysis of the time-course showed that the effect on exacerbations was evident at 6 months (risk ratio $0 \cdot 70, p=0.108$ at 3 months; risk ratio $0.79, p=0.002$ at 6 months; risk ratio $0.73, p=0.002$ at 9 months) [129].

\subsection{Erdosteine}

Erdosteine ( $\mathrm{N}$-carboximetinylthioacetyl-acetyl-homocysteinatiolacotone) is a synthetic derivative of the natural amino acid methionine [130]. This drug contains two sulfhydryl groups; once the bonds are broken, the release of these two groups allows the disulphide to bind to the mucins [130]. The potential reduction of sulfhydryl groups also has antioxidant properties [131].

\subsubsection{Controlled clinical trials of erdosteine during COPD exacerbations}

The RESTORE (Reducing Exacerbations and Symptoms by Treatment with ORal Erdosteine in COPD) study was a phase III multinational, randomised, double-blind, placebo-controlled parallel group study that randomised COPD patients to erdosteine $(n=228)$ or placebo $(n=239)$ added to usual maintenance therapy for 12 months after a 2-week run-in period [132]. The study reported no statistically significant difference between treatment groups in mean number of exacerbations after 
12 months (2.39 versus 2.30 exacerbations for erdosteine and placebo respectively). However, erdosteine treatment was associated with a $24.6 \%$ decrease in the duration of all exacerbations (9.5 \pm 7.2 days with erdosteine versus $12.6 \pm 9.7$ days with placebo; $p=0.023)$ [132]. Exacerbations in this study were defined as a symptomatic worsening beyond normal day-to-day variations requiring a change in regular medication and/or healthcare resources utilisation: mild (increased use of bronchodilators), moderate (treatment with antibiotics and/or systemic corticosteroids and additional medical assistance) and severe (visit to an emergency department/hospitalisation).

Two double-blind randomised controlled trials also assessed erdosteine in combination with antibacterial therapy in patients with COPD exacerbations. The first study was double-blind, parallel group study that evaluated 237 COPD patients treated with erdosteine or placebo in association with amoxicillin for a minimal of 7 days, maximum of 10 days [133]. Exacerbations were defined by the presence of functional signs of chronic bronchitis in the exacerbation phase according to ATS standard (1987). Concomitant treatments with mucoactives, anti-inflammatories including glucocorticoids, oral beta2-agonists, diuretics, anticholinergics, anti-histamines and calcium blockers were avoided during the trial, but inhaled beta2-agonist were allowed as required except for the last 12 hours before each clinical visit [133].

The global clinical assessment (GCA) was chosen as the primary end point as a general indication of activity with objective/subjective evaluation of the clinical picture. GCA is a cumulative index composed of 6 items; 2 related to sputum parameters (appearance and viscosity), and 4 to functional signs of chronic bronchitis (difficulty to expectorate, catarrh at auscultation, cough, dyspnoea intensity). COPD patients treated with erdosteine had a more rapid reduction in GCA score [a reduction of 3.88 (from 12.25 to 8.37 ) vs. 2.83 (from 12.70 to 9.87 ) compared with placebo over days $0-4$; and 3.45 (from 8.37 to 4.92 ) vs. 2.49 (9.87 to 7.38 ) with placebo over days $5-10$ $(p<0.01$ for first and last days)] [133]. Secondary endpoints of efficacy including sputum volume 
and spirometry parameters were not statistically different between treatments and no differences in safety measures were discerned [133].

The second trial involved COPD patients with an exacerbation $(n=200)$ and body temperature above $38^{\circ} \mathrm{C}$. Patients received ciprofloxacin, plus either erdosteine or placebo, for 7 days [134]. By days 3 and 8, the global assessment score had fallen more in those treated with erdosteine (by 2.45 vs. 1.91 with placebo, $p=0.001$ by day 3 ; and by 3.03 vs. 2.33 with placebo, $p=0.01$ by day 8 ) [134].

\subsection{N-acetylcysteine}

$\mathrm{N}$-acetylcysteine (NAC) hydrolyzes the disulfide bonds of mucus proteins. In vitro and animal models indicate that NAC also has antioxidant and antiinflammatory properties. The effectiveness of NAC treatment of COPD patients in stable phase and during COPD exacerbation is still controversial [135]. Orally administered NAC does not penetrate into the lower airways or bronchial lavage fluid [136] and inhaled NAC $(\mathrm{pH} 2.2)$ can cause bronchoconstriction and airway inflammation [137].

\subsubsection{Controlled clinical trials of $\mathrm{N}$-acetylcysteine in stable COPD}

BRONCHUS (Bronchitis Randomized On NAC Cost-Utility Study) was a large phase III, doubleblind, randomised placebo-controlled parallel-group trial that randomised COPD patients (GOLD stage 2 and 3 ) to oral NAC added to usual maintenance therapy ( $n=256)$ versus placebo added to usual maintenance therapy $(n=267)$ for 3 years [138]. The decline in FEV1 and reduction in diffusion capacity were not significantly different between the NAC group and the placebo group [138]. Furthermore, yearly exacerbation (defined as an increase in dyspnoea, cough, or both 
associated with a change in quality and quantity of sputum, which led the patient to seek medical attention and which lasted for at least 3 days) rates were also not statistically significant between the two groups [138]. However, in COPD patients who were not taking inhaled glucocorticoids $(n=155)$, the risk of exacerbation was lower in patients treated with NAC compared with patients treated with placebo $(p=0.040)$. This was significant for moderate or severe exacerbations compared with placebo group $(p=0.032)[138]$.

In a 3-year placebo controlled randomised controlled phase IV trial, 286 patients with stable COPD (14\% mild, $47 \%$ moderate, $17 \%$ severe) or former smokers with chronic bronchitis with normal lung function $(n=22 \%)$, were randomised to oral NAC added to usual maintenance therapy $(n=96)$ or to inhaled fluticasone propionate added to usual maintenance therapy $(n=94)$ or to placebo added to usual maintenance therapy ( $n=96)$ [139]. Patients in the NAC group showed 1.35 times increased exacerbation rates compare with the placebo group although this did not reach significance $(p=0.054)$. Exacerbations were defined as an episode with one or more subsequent unscheduled contacts with either a general practitioner or a chest physician due to worsening of respiratory symptoms; the exacerbation was labelled as 'mild' if no course of prednisolone and/or antibiotics was prescribed, exacerbations were labelled as 'moderate' if were treated with prednisolone and/or antibiotics, exacerbations leading to an emergency room visit or hospitalization were defined 'severe'.

In a more recent study, the High-Dose N-Acetylcysteine (HIACE), 1-year, double-blind, randomised, placebo-controlled trial, 120 stable COPD patients $(n=120)$ were randomized to NAC added to usual maintenance therapy $(n=58)$ or placebo added to usual maintenance therapy $(n=62)$ for 1 year [140]. There were no statistically significant differences in forced expiratory flow (FEF) $25 \%-75 \%$ between study groups at baseline but after 1 year follow-up, there was a significant increase in FEF $25 \%-75 \%$ in the NAC group (from $0.72 \pm 0.07 \mathrm{~L} / \mathrm{s}$ to $0.80 \pm 0.07 \mathrm{~L} / \mathrm{s}$ ) compared with FEF $25 \%-75 \%$ in the placebo group (from $0.679 \pm 0.07 \mathrm{~L} / \mathrm{s}$ to $0.677 \pm 0.07 \mathrm{~L} / \mathrm{s}$ ) 
$(p=0.037)$. Despite this, there were no significant differences in other spirometric parameters $\left[\mathrm{FEV}_{1}, \mathrm{FVC}\right.$ and inspiratory capacity (IC)] between the two groups. In contrast, reactance as measured by forced oscillometry improved significantly in the NAC group compared with the placebo group $(p=0.04)$. In addition, the frequency resonance (the frequency at which reactance equals zero) was significantly reduced in the NAC group compared with placebo group $(p=0.02)$ [140].

The mean frequency of COPD exacerbations as defined by two of the following three symptoms increase in shortness of breath, volume, or purulence of sputum in the NAC group was significantly reduced compared to the placebo group (reduction rate 0.75) during the year (NAC 0.96/y vs placebo 1.71/y; $p=0.019$ ) [140]. However, the proportion of exacerbation-free patients in the NAC group at the end of the study vs placebo $(53.8 \%$ vs $37.5 \%)$ did not reach statistical significance $(p=0.088)[140]$.

\subsubsection{Controlled clinical trials of $\mathbf{N}$-acetylcysteine in COPD exacerbations}

A randomised, double-blind placebo-controlled trial evaluated a total of 50 patients admitted to the hospital for acute COPD exacerbation. Patients were randomised within 24 hours of admission to oral NAC $(n=25)$ or placebo $(n=25)$ added to concurrent treatment with prednisone, nebulised salbutamol four times daily and, where appropriate, antibiotics. Treatment was continued for 7 days or until discharge whichever occurred first. Patients with heart failure or pneumonia were excluded from the study [141]. No statistically significant differences were shown in a seven-point Likert scale for measuring breathlessness or in lung function. The median length of hospital stay was 6 days in the NAC group and 5.5 days in the placebo group. 


\subsection{Recombinant human DNase}

Sputum contains products of inflammation including DNA and filamentous actin (F-actin) polymers. DNA and F-actin copolymerize to form a rigid network entangled with the mucin gel [142]. Leukocyte-derived DNA increases mucus viscosity in pulmonary secretions. Extracellular DNA can be cleaved by deoxyribonuclease I (Dnase), a naturally occurring enzyme. Dornase alfa is the recombinant form of human Dnase. Dornase alfa was first investigated in patients with cystic fibrosis [143].

\subsubsection{Controlled clinical trials of dornase alfa in COPD exacerbations}

Unfortunately, clinical trials using dornase alfa have never been published as full articles but information can be collected from various abstracts and reviews [144, 145]. The use of dornase alfa was investigated in the COMET (The Chronic obstructive pulmonary disease Mortality Endpoint Trial) study, a large phase III study, in COPD patients $(n=3731)$ during hospital treatment for an exacerbation [144]. COPD patients were randomly assigned to a 14-days treatment with dornase alfa or placebo twice daily added to usual maintenance therapy [144]. 90-day all-cause mortality was $10.3 \%$ for the dornase alfa-treated COPD exacerbation group and $9.5 \%$ for the placebo-treated COPD exacerbation group $(p=0.43)$ [144]. In addition, general 90-day adverse events were comparable between the two groups [144].

14. Novel compounds in development for the treatment of COPD patients acting on mucin synthesis/secretion/structure 
Many aspects of the mucin assembly, storage and secretion have been therapeutically targeted to reduce mucin synthesis and secretion. A number of inhibitors of these targets are in the process of being developed for clinical use and they are summarised in Table 6 [146].

\section{Conclusion}

In conclusion, the evidence accumulated in the last decade has begun to reveal the enormous complexity of the expression, interactions and functions of the large number of different mucins in the different compartments of the human lower airways, both in normal subjects and in patients with different clinical phases and stages of COPD severity. It is evident that the simplistic view that mucus hypersecretion in patients with COPD is associated with negative clinical outcomes and that we need to treat COPD with "mucolytic drugs" is a gross underestimation of the complexity of this molecular network. We definitely need more human translational research studies in this area. Likewise, our current knowledge of the effects of the drugs already available on the market for the treatment of COPD patients on mucin synthesis/secretion/structure in human lower airways is extremely limited and often indirect and again we need more controlled clinical trials in this area focusing on these effects. The data within this review may help to provide a rationale for the future development of novel compounds that modulate mucin synthesis/secretion/structure in the human lower airways of these patients.

\section{Expert opinion}

Mucins are the main component of sputum and they determine its specific viscoelastic and rheological properties. Many patients with COPD have chronic bronchitis with increased sputum production and the presence of chronic bronchitis is a predictor of COPD-related death, increased 
risk of pneumonia and of an accelerated decline in lung function. Indeed, the severity of COPD is related with the amount of mucus in the human lower airways. In addition, the activity of the lower airway mucin-secreting cells and mucin production is modulated by both inflammatory mediators and infectious agents both of which also alter mucociliary clearance and the immune defences of the human lower airways. However, infection does not just simply up-regulate the expression of mucins as many respiratory virus infections and bacterial products can both up- or down-regulate mucin-secreting cells differentiation and mucins secretion as the effect may differ depending upon clinical status. This has implications for clinical studies using mucolytics.

The role of mucins in the pathogenesis of stable COPD differs from that in the pathogenesis of COPD exacerbations. Increased mucin presence in the sputum of COPD patients may be caused by a complex interaction between (i) increased numbers of mucin-secreting cells and (ii) changes in the amounts of mucins synthesized and/or secreted by each of these cells. Furthermore, COPD patients may have more subtle changes in the biochemical structure of the mucins and/or of their interactions with other components of the epithelial lining fluid, including microbiota.

Unfortunately, only a few well-designed studies have examined the potential contribution of mucins in the pathogenesis of stable COPD and in the pathogenesis of COPD exacerbations. This reflects the knowledge base of mucin involvement in COPD and the efficacy of current mucintargeted drugs. The therapeutic value of mucoactive drugs and mucin synthesis/secretion/structure modulators is still controversial, particularly on the light of recent studies showing the fundamental role of many mucins in the innate immune responses of the human lower airways. In addition, many studies appear to be conducted without examining the effect on mucin production within the airway. Of note, there is an absence of controlled clinical trials investigating the effects of currently available COPD therapeutic agents including inhaled and/or systemic glucocorticoids, inhaled antimuscarinics, inhaled beta2-agonists, phosphodiesterase-4 inhibitors and macrolides on mucin synthesis/secretion/structure. 
Mucins are either secreted or in a transmembrane form. The major secreted polymeric mucins of the human lower airways are MUC5AC and MUC5B. However, the genetic and epigenetic pathways modulating their synthesis and secretion within human lower airways are not yet clarified despite the wealth of knowledge concerning the succession of steps involved in MUC5AC and MUC5B assembly, storage and secretion across different intracellular and extracellular compartments. A greater understanding of the mechanisms of mucin production in primary human airway epithelial cells and how this varies with disease status and response to infectious agents is necessary in order to provide more rational approaches to mucus targeting.

Several mucin synthesis/secretion/structure modulators are used to treat COPD patients, but their mechanisms of action are still not fully characterized, and these drugs/compounds often have a plethora of additional anti-inflammatory and antioxidant effects. For these reasons some beneficial clinical effects produced by these drugs/compounds are not only due to their action on the mucins.

Overall, the view that mucus hypersecretion in COPD is associated with negative clinical outcomes and that COPD needs to be treated with "mucolytic drugs" is a gross oversimplification of the complexity of this molecular network. Likewise, our knowledge of drug effects on mucin synthesis/secretion/structure in the human airways is extremely limited and often indirect. We definitively need more human translational research studies in this area and better, preferably noninvasive, means of characterising differential mucus production in these patients to provide proofof-mechanism analysis to correlate with improved clinical measures of small airways disease such as forced oscillometry. 


\section{Funding}

This paper was not funded.

\section{Declaration of interest}

The authors have no relevant affiliations or financial involvement with any organization or entity with a financial interest in or financial conflict with the subject matter or materials discussed in the manuscript. This includes employment, consultancies, honoraria, stock ownership or options, expert testimony, grants or patents received or pending, or royalties.

\section{Reviewer disclosures}

Peer reviewers on this manuscript have no relevant financial or other relationships to disclose.

\section{Acknowledgments}

PMH is funded by a Fellowship and grants from the NHMRC $(1079187,1175134)$. 


\section{References}

1. Torelman NG. The daily amount of tracheobronchial secretions in man. Acta Otolaryngol. 1960; 158(suppl43).

2. Yeager H. Tracheobronchial secretions. Am J. Med. 1971;50(4):493-509.

3. Bansil R, Turner BS. The biology of mucus: Composition, synthesis and organization. Adv Drug Deliv Rev. 2018;124:3-15.

${ }^{*}$ This review article provides an updated overview of the biological composition of mucus and mechanisms of mucins synthesis and secretion.

4. Johansson MEV, Hansson GC. The mucins. Encyclopedia of Immunobiology. 2016;2:381-388.

5. Corfield AP. Mucins: a biologically relevant glycan barrier in mucosal protection. Biochimica et biophysica acta. 2015;1850(1):236-252.

6. Symmes BA, Stefanski AL, Magin CM, et al. Role of mucins in lung homeostasis: regulated expression and biosynthesis in health and disease. Biochem Soc Trans. 2018;46(3):707-719.

7. Desseyn JL, Aubert JP, Porchet N, et al. Evolution of the large secreted gel-forming mucins. Mol Biol Evol. 2000;17(8):1175-1184.

8. Lang T, Hansson GC, Samuelsson T. Gel-forming mucins appeared early in metazoan evolution. Proc Natl Acad Sci U S A. 2007;104(41):16209-16214.

9. Linden SK, Sutton P, Karlsson NG, et al. Mucins in the mucosal barrier to infection. Mucosal Immunol. 2008;1(3):183-197.

10. Sheehan JK, Oates K, Carlstedt I. Electron microscopy of cervical, gastric and bronchial mucus glycoproteins. Biochem J. 1986;239(1):147-153.

11. Ridley C, Thornton DJ. Mucins: the frontline defence of the lung. Biochem Soc Trans. 2018;46(5):1099-1106.

*This review article provides an updated overview of mechanisms that underline the defence of the lung and their possible involvment in lung diseases.

12. Hijikata M, Matsushita I, Tanaka G, et al. Molecular cloning of two novel mucin-like genes in the disease-susceptibility locus for diffuse panbronchiolitis. Hum Genet. 2011;129(2):117-128.

13. Ma J, Rubin BK, Voynow JA. Mucins, Mucus, and Goblet Cells. Chest. 2018;154(1):169-176.

14. Rose MC, Voynow JA. Respiratory tract mucin genes and mucin glycoproteins in health and disease. Physiol Rev. 2006;86(1):245-278.

15. Yoshimoto T, Matsubara D, Soda M, et al. Mucin 21 is a key molecule involved in the incohesive growth pattern in lung adenocarcinoma. Cancer Sci. 2019;110(9):3006-3011.

16. Nakano Y, Yang IV, Walts AD, et al. MUC5B Promoter Variant rs35705950 Affects MUC5B Expression in the Distal Airways in Idiopathic Pulmonary Fibrosis. Am J Respir Crit Care Med. 2016;193(4):464-466.

17. Hunninghake $\mathrm{GM}$, Hatabu $\mathrm{H}$, Okajima $\mathrm{Y}$, et al. MUC5B promoter polymorphism and interstitial lung abnormalities. N Engl J Med. 2013;368(23):2192-2200.

18. Seibold MA, Wise AL, Speer MC, et al. A common MUC5B promoter polymorphism and pulmonary fibrosis. N Engl J Med. 2011;364(16):1503-1512.

19. Evans CM, Fingerlin TE, Schwarz MI, et al. Idiopathic Pulmonary Fibrosis: A Genetic Disease That Involves Mucociliary Dysfunction of the Peripheral Airways. Phys Rev. 2016;96(4):15671591.

20. Jaramillo AM, Azzegagh Z, Tuvim MJ, et al. Airway Mucin Secretion. Ann Am Thorac Soc. 2018;15(Suppl 3):S164-S170.

21. Birchenough GM, Johansson ME, Gustafsson JK, et al. New developments in goblet cell mucus secretion and function. Mucosal Immunol. 2015;8(4):712-719.

22. Davis CW, Dickey BF. Regulated airway goblet cell mucin secretion. Annu Rev Physiol. 2008;70:487-512. 
23. Dhanisha SS, Guruvayoorappan C, Drishya S, et al. Mucins: Structural diversity, biosynthesis, its role in pathogenesis and as possible therapeutic targets. Crit Rev Oncol Hematol.

2018;122:98-122.

${ }^{* *}$ This review article provides an updated overview of all the mucins in human tissues and their role in different pathological conditions.

24. Reid AT, Veerati PC, Gosens R, et al. Persistent induction of goblet cell differentiation in the airways: Therapeutic approaches. Pharmacol Therapeut. 2018;185:155-169.

25. Benam KH, Vladar EK, Janssen WJ, et al. Mucociliary Defense: Emerging Cellular, Molecular, and Animal Models. Ann Am Thorac Soc. 2018;15(Suppl 3):S210-S215.

26. Jin C, Kenny DT, Skoog EC, et al. Structural Diversity of Human Gastric Mucin Glycans. Mol Cell Proteomics. 2017;16(5):743-758.

27. Inoue D, Yamaya M, Kubo H, et al. Mechanisms of mucin production by rhinovirus infection in cultured human airway epithelial cells. Resp Physiol Neurobi. 2006;154(3):484-499.

28. Inoue D, Kubo H, Sasaki T, et al. Erythromycin attenuates MUC5AC synthesis and secretion in cultured human tracheal cells infected with RV14. Respir. 2008;13(2):215-220.

29. Liu T, Zhou YT, Wang LQ, et al. NOD-like receptor family, pyrin domain containing 3 (NLRP3) contributes to inflammation, pyroptosis, and mucin production in human airway epithelium on rhinovirus infection. J Allergy Clin Immunol. 2019;144(3):777-787.e9.

30. Zhu L, Lee P-K, Lee W-M, et al. Rhinovirus-induced major airway mucin production involves a novel TLR3-EGFR-dependent pathway. Am J Respir Cell Mol Biol. 2009;40(5):610-619.

31. Chen G, Korfhagen TR, Karp CL, et al. Foxa3 induces goblet cell metaplasia and inhibits innate antiviral immunity. Am J Respir Crit Care Med. 2014;189(3):301-313.

32. Starkey MR, Jarnicki AG, Essilfie A-T, et al. Murine models of infectious exacerbations of airway inflammation. Curr Opin Pharm. 2013;13(3):337-344.

33. Jing $Y$, Gimenes JA, Mishra R, et al. NOTCH3 contributes to rhinovirus-induced goblet cell hyperplasia in COPD airway epithelial cells. Thorax. 2019;74(1):18-32.

34. Cohen M, Zhang X-Q, Senaati HP, et al. Influenza A penetrates host mucus by cleaving sialic acids with neuraminidase. Virol Jl. 2013;10:321.

35. Hsu AC-Y, Starkey MR, Hanish I, et al. Targeting PI3K-p110a Suppresses Influenza Virus Infection in Chronic Obstructive Pulmonary Disease. Am J Respir Crit Care Med. 2015;191(9):1012-1023.

36. McAuley JL, Corcilius L, Tan HX, et al. The cell surface mucin MUC1 limits the severity of influenza A virus infection. Mucos Imm. 2017;10(6):1581-1593.

37. Hsu C-C, Su T-W, Chen P-H. Pool boiling of nanoparticle-modified surface with interlaced wettability. Nanoscale Res Lett. 2012;7(1):259.

38. Nakamura S, Horie M, Daidoji T, et al. Influenza A Virus-Induced Expression of a GaINAc Transferase, GALNT3, via MicroRNAs Is Required for Enhanced Viral Replication. J Virol. 2015;90(4):1788-1801

39. Barbier D, Garcia-Verdugo I, Pothlichet J, et al. Influenza A induces the major secreted airway mucin MUC5AC in a protease-EGFR-extracellular regulated kinase-Sp1-dependent pathway. Am J Respir Cell Mol Biol. 2012;47(2):149-157.

40. Ehre $\mathrm{C}$, Worthington EN, Liesman RM, et al. Overexpressing mouse model demonstrates the protective role of Muc5ac in the lungs. Proc Natl Acad Sci U S A. 2012;109(41):16528-16533.

41. Villenave R, Thavagnanam S, Sarlang $S$, et al. In vitro modeling of respiratory syncytial virus infection of pediatric bronchial epithelium, the primary target of infection in vivo. Proc Natl Acad Sci U S A. 2012;109(13):5040-5045.

42. Li Y, Dinwiddie DL, Harrod KS, et al. Anti-inflammatory effect of MUC1 during respiratory syncytial virus infection of lung epithelial cells in vitro. Am J Physiol Lung Cell Mol Physiol. 2010;298(4):L558-L563. 
43. Baños-Lara Mdel R, Piao B, Guerrero-Plata A. Differential mucin expression by respiratory syncytial virus and human metapneumovirus infection in human epithelial cells. Mediators Inflamm. 2015;2015:347292.

44. Mata M, Martinez I, Melero JA, et al. Roflumilast inhibits respiratory syncytial virus infection in human differentiated bronchial epithelial cells. PloS one. 2013;8(7):e69670.

45. Hashimoto K, Graham BS, Ho SB, et al. Respiratory syncytial virus in allergic lung inflammation increases Muc5ac and gob-5. Am J Respir Crit Med. 2004;170(3):306-312.

46. Persson $B D$, Jaffe $A B$, Fearns $R$, et al. Respiratory syncytial virus can infect basal cells and alter human airway epithelial differentiation. PloS one. 2014;9(7):e102368.

47. Kyo Y, Kato K, Park YS, et al. Antiinflammatory role of MUC1 mucin during infection with nontypeable Haemophilus influenzae. Am J Respir Cell Mol Biol. 2012;46(2):149-156.

48. Jono $\mathrm{H}$, Shuto $\mathrm{T}, \mathrm{Xu} \mathrm{H}$, et al. Transforming growth factor-beta -Smad signaling pathway cooperates with NF-kappa B to mediate nontypeable Haemophilus influenzae-induced MUC2 mucin transcription. J Biol Chem. 2002;277(47):45547-45557.

49. Wang $\mathrm{H}$, Brautigan DL. A novel transmembrane Ser/Thr kinase complexes with protein phosphatase-1 and inhibitor-2. J Biol Chem. 2002;277(51):49605-49612.

50. Huang $\mathrm{Y}$, Mikami $\mathrm{F}$, Jono $\mathrm{H}$, et al. Opposing roles of PAK2 and PAK4 in synergistic induction of MUC5AC mucin by bacterium NTHi and EGF. Biochem Biophys Res Commun. 2007;359(3):691-696.

51. Shen H, Yoshida H, Yan F, et al. Synergistic induction of MUC5AC mucin by nontypeable Haemophilus influenzae and Streptococcus pneumoniae. Biochem Biophys Res Commun. 2008;365(4):795-800.

52. Moghaddam SJ, Clement CG, De la Garza MM, et al. Haemophilus influenzae lysate induces aspects of the chronic obstructive pulmonary disease phenotype. Am J Respir Cell Mol Biol. 2008;38(6):629-638.

53. Ganesan S, Comstock AT, Kinker B, et al. Combined exposure to cigarette smoke and nontypeable Haemophilus influenzae drives development of a COPD phenotype in mice. Resp Res. 2014;15:11.

54. Jono $\mathrm{H}, \mathrm{Xu} \mathrm{H}$, Kai H, et al. Transforming growth factor-beta-Smad signaling pathway negatively regulates nontypeable Haemophilus influenzae-induced MUC5AC mucin transcription via mitogen-activated protein kinase (MAPK) phosphatase-1-dependent inhibition of p38 MAPK. J Biol Chem. 2003;278(30):27811-27819.

55. Lillehoj EP, Guang W, Hyun SW, et al. Neuraminidase 1-mediated desialylation of the mucin 1 ectodomain releases a decoy receptor that protects against Pseudomonas aeruginosa lung infection. J Biol Chem. 2019;294(2):662-678.

56. Lillehoj EP, Hyun SW, Kim BT, et al. Muc1 mucins on the cell surface are adhesion sites for Pseudomonas aeruginosa. Am J Physiol Lung Cell Mol Physiol. 2001;280(1): L181-L187.

57. Kato K, Uchino R, Lillehoj EP, et al. Membrane-Tethered MUC1 Mucin Counter-Regulates the Phagocytic Activity of Macrophages. Am J Respir Cell Mol Biol. 2016;54(4):515-523.

58. Kato K, Hanss AD, Zemskova MA, et al. Pseudomonas aeruginosa increases MUC1 expression in macrophages through the TLR4-p38 pathway. Biochem Biophys Res Commun. 2017;492(2):231-235.

59. Ben Mohamed F, Mohamed FB, Garcia-Verdugo I, et al. A crucial role of Flagellin in the induction of airway mucus production by Pseudomonas aeruginosa. PloS one. 2012;7(7):e39888.

60. Lu W, Hisatsune A, Koga T, et al. Cutting edge: enhanced pulmonary clearance of Pseudomonas aeruginosa by Muc1 knockout mice. J Immu. 2006;176(7):3890-3894.

61. Lee S, Chung Y-J, Kim B-H, et al. Comparative pharmacokinetic evaluation of two formulations of bicalutamide 50-mg tablets: an open-label, randomized-sequence, single-dose, two-period crossover study in healthy Korean male volunteers. Clin Ther. 2009;31(12):3000-3008. 
62. Thornton DJ, Rousseau K, McGuckin MA. Structure and function of the polymeric mucins in airways mucus. Ann Rev Phys. 2008;70:459-486.

63. Lee SR, Kim WT, Kim TN, et al. Association between the length of the MUC8-minisatellite 5 region and susceptibility to chronic obstructive pulmonary disease (COPD). Genes Genom. 2018;40(1):123-127.

** This article provides new interesting knowledge of mucins gene analysis, showing a relationship between MUC8 minisatellites and COPD pathogenesis

64. Peljto AL, Zhang Y, Fingerlin TE, et al. Association between the MUC5B promoter polymorphism and survival in patients with idiopathic pulmonary fibrosis. JAMA. 2013;309(21):2232-2239.

65. Ash SY, Harmouche R, Putman RK, et al. Association between acute respiratory disease events and the MUC5B promoter polymorphism in smokers. Thorax. 2018;73(11):1071-1074.

66. Chung JH, Peljto AL, Chawla A, et al. CT Imaging Phenotypes of Pulmonary Fibrosis in the MUC5B Promoter Site Polymorphism. Chest. 2016;149(5):1215-1222.

67. Openshaw PJ, Turner-Warwick M. Observations on sputum production in patients with variable airflow obstruction; implications for the diagnosis of asthma and chronic bronchitis. Res Med. 1989;83(1):25-31.

68. Allinson JP, Hardy R, Donaldson GC, et al. The Presence of Chronic Mucus Hypersecretion across Adult Life in Relation to Chronic Obstructive Pulmonary Disease Development. Am J Respir Crit Care Med. 2016;193(6):662-672.

69. Kim V, Criner GJ. Chronic bronchitis and chronic obstructive pulmonary disease. Am J Respir Crit Care Med. 2013;187(3):228-237.

70. Vestbo J, Prescott E, Almdal T, et al. Body mass, fat-free body mass, and prognosis in patients with chronic obstructive pulmonary disease from a random population sample: findings from the Copenhagen City Heart Study. Am J Respir Crit Care Med. 2006;173(1):79-83.

71. Khurana S, Ravi A, Sutula J, et al. Clinical characteristics and airway inflammation profile of COPD persistent sputum producers. Res Med. 2014;108(12):1761-1770.

72. Anderson WH, Coakley RD, Button B, et al. The Relationship of Mucus Concentration (Hydration) to Mucus Osmotic Pressure and Transport in Chronic Bronchitis. Am J Respir Crit Care Med. 2015;192(2):182-190.

73. Kirkham S, Kolsum U, Rousseau K, et al. MUC5B is the major mucin in the gel phase of sputum in chronic obstructive pulmonary disease. Am J Respir Crit Care Med. 2008;178(10):1033-1039.

74. Kesimer M, Ford AA, Ceppe A, et al. Airway Mucin Concentration as a Marker of Chronic Bronchitis. N Eng J Med. 2017;377(10):911-922.

${ }^{* *}$ This review article explore the role of mucin conentration in sputum as a potential biomarker in COPD patients and a potential terhapeutic target.

75. Caramori G, Casolari P, Di Gregorio C, et al. MUC5AC expression is increased in bronchial submucosal glands of stable COPD patients. Histopathology. 2009;55(3):321-331.

76. Reid L. Measurement of the bronchial mucous gland layer: a diagnostic yardstick in chronic bronchitis. Thorax. 1960;15:132-141.

77. Innes AL, Woodruff PG, Ferrando RE, et al. Epithelial mucin stores are increased in the large airways of smokers with airflow obstruction. Chest. 2006;130(4):1102-1108.

78. Kim V, Oros M, Durra H, et al. Chronic bronchitis and current smoking are associated with more goblet cells in moderate to severe COPD and smokers without airflow obstruction. PLoS One. 2015;10:e0116108.

79. Song J, Heijink IH, Kistemaker LEM, et al. Aberrant DNA methylation and expression of SPDEF and FOXA2 in airway epithelium of patients with COPD. Clin Epigenetics. 2017;9:42.

80. Ghosh A, Coakley RC, Mascenik T, et al. Chronic E-Cigarette Exposure Alters the Human Bronchial Epithelial Proteome. Am J Respir Crit Care Med. 2018;198(1):67-76. 
81. Hogg JC. Pathophysiology of airflow limitation in chronic obstructive pulmonary disease. Lancet. 2004;364(9435):709-721.

82. Hogg JC, Macklem PT, Thurlbeck WM. Site and nature of airway obstruction in chronic obstructive lung disease. N Eng J Med. 1968;278(25):1355-1360.

83. Hogg JC, Chu FSF, Tan WC, et al. Survival after lung volume reduction in chronic obstructive pulmonary disease: insights from small airway pathology. Am J Respir Crit Care Med. 2007;176(5):454-459.

84. Caramori G, Di Gregorio C, Carlstedt I, et al. Mucin expression in peripheral airways of patients with chronic obstructive pulmonary disease. Histopathology. 2004;45(5):477-484.

85. Yu Q, Yang D, Chen X, et al. CD147 increases mucus secretion induced by cigarette smoke in COPD. BMC Pulm Med. 2019;19(1):29.

86. Fernández-Blanco JA, Fakih D, Arike L, Rodríguez-Piñeiro AM, et al. Attached stratified mucus separates bacteria from the epithelial cells in COPD lungs. JCI Insight. 2018;3(17). pii:120994.

87. Sibila O, Mateus EF, Restrepo MI, et al. Reply: Measuring Airway Mucin 2 in Patients with Severe Chronic Obstructive Pulmonary Disease with Bacterial Colonization. Ann Am Thor Soc. 2016;13(11):2104-2105.

88. Yilmaz MB, Zorlu A, Dogan OT, et al. Role of CA-125 in identification of right ventricular failure in chronic obstructive pulmonary disease. Clin Card. 2011;34(4):244-248.

89. Barouchos N, Papazafiropoulou A, lacovidou N, et al. Comparison of tumor markers and inflammatory biomarkers in chronic obstructive pulmonary disease (COPD) exacerbations. Scand J Clin Lab Inves. 2015;75(2):126-132.

90. Chillappagari S, Preuss J, Licht S, et al. Altered protease and antiprotease balance during a COPD exacerbation contributes to mucus obstruction. Resp Res. 2015;16:85.

91. Zheng Z, Qi Y, Xu X, et al. Sputum mucin 1 is increased during the acute phase of chronic obstructive pulmonary disease exacerbation. J Thor Dis. 2017;9(7):1873-1882.

92. Montalbano AM, Albano GD, Anzalone G, et al. Cigarette smoke alters non-neuronal cholinergic system components inducing MUC5AC production in the $\mathrm{H} 292$ cell line. Eur $\mathrm{J}$ Pharm. 2014;736:35-43.

93. Ishinaga $\mathrm{H}$, Takeuchi $\mathrm{K}$, Kishioka $\mathrm{C}$, et al. Effects of dexamethasone on mucin gene expression in cultured human nasal epithelial cells. Laryngoscope. 2002;112(8 Pt 1):14361440.

94. Kanoh S, Tanabe T, Rubin BK. IL-13-induced MUC5AC production and goblet cell differentiation is steroid resistant in human airway cells. Clin Exp Allergy. 2011;41(12):17471756.

95. Leigh R, Mostafa MM, King EM, et al. An inhaled dose of budesonide induces genes involved in transcription and signaling in the human airways: enhancement of anti- and proinflammatory effector genes. Pharmacol Res Perspect. 2016;4(4):e00243.

96. Poletti $D$, lannini $V$, Casolari $P$, et al. Nasal inflammation and its response to local glucocorticoid regular treatment in patients with persistent non-allergic rhinitis: a pilot study. $J$ Inflamm. 2016;13:26.

97. Meltzer EO, Jalowayski AA, J. Nasal cytology in clinical practice. Am J Rhinol Allergy. 1988;2:47-54.

98. Singanayagam A, Glanville N, Girkin JL, et al. Corticosteroid suppression of antiviral immunity increases bacterial loads and mucus production in COPD exacerbations. Nat Commun. 2018;9(1):2229.

99. Singanayagam A, Glanville N, Cuthbertson L, et al. Inhaled corticosteroid suppression of cathelicidin drives dysbiosis and bacterial infection in chronic obstructive pulmonary disease. Sci Transl Med. 2019;11(507).

100. Gollub EG, Waksman H, Goswami S, et al. Mucin genes are regulated by estrogen and dexamethasone. Biochem Biophys Res Commun. 1995;217(3):1006-1014. 
101. Kai H, Yoshitake K, Hisatsune A, et al. Dexamethasone suppresses mucus production and MUC-2 and MUC-5AC gene expression by NCl-H292 cells. Am J Physiol. 1996;271(3 Pt 1):L484-L488.

102. Kistemaker LEM, Gosens R. Acetylcholine beyond bronchoconstriction: roles in inflammation and remodeling. Trends Pharmacol Sci. 2015;36(3):164-171.

103. Kistemaker LEM, Bos ST, Mudde WM, et al. Muscarinic $M_{3}$ receptors contribute to allergeninduced airway remodeling in mice. Am J Respir Cell Mol Biol. 2014;50(4):690-698.

104. Hasani A, Toms N, Agnew JE, et al. The effect of inhaled tiotropium bromide on lung mucociliary clearance in patients with COPD. Chest. 2004;125(5):1726-1734.

105. Meyer $T$, Reitmeir $P$, Brand $P$, et al. Effects of formoterol and tiotropium bromide on mucus clearance in patients with COPD. Res Med. 2011;105(6):900-906.

106. Salathe M. Effects of beta-agonists on airway epithelial cells. J Allergy Clin Immunol 2002;110(6 Suppl):S275-S281.

107. Jones PW, Bosh TK. Quality of life changes in COPD patients treated with salmeterol. Am J Respir Crit Care Med. 1997;155(4):1283-1289.

108. Mahler DA, Donohue JF, Barbee RA, et al. Efficacy of salmeterol xinafoate in the treatment of COPD. Chest. 1999;115(4):957-965.

109. Devalia JL, Sapsford RJ, Rusznak C, et al. The effects of salmeterol and salbutamol on ciliary beat frequency of cultured human bronchial epithelial cells, in vitro. Pulm Pharm. 1992;5(4):257-263.

110. Nguyen LP, Lin R, Parra S, et al. Beta2-adrenoceptor signaling is required for the development of an asthma phenotype in a murine model. P Natl Acad Sci U S A. 2009;106(7):2435-40.

111. Nguyen LP, Omoluabi O, Parra S, et al. Chronic exposure to beta-blockers attenuates inflammation and mucin content in a murine asthma model. Am J Resp Cell Mol. 2008;38(3):256-262.

112. Mata M, Sarriá B, Buenestado A, et al. Phosphodiesterase 4 inhibition decreases MUC5AC expression induced by epidermal growth factor in human airway epithelial cells. Thorax. 2005;60(2):144-152.

113. Asaka N, Kakuo H, Ohmori K, et al. Effects of the new benzimidazole derivative TAS-203, an orally active phosphodiesterase 4 inhibitor, on airway inflammation in rats and emetic responses in ferrets. Arzneimittel-Forsch. 2010;60(9):564-570.

114. Demizu S, Asaka N, Kawahara H, et al. TAS-203, an oral phosphodiesterase 4 inhibitor, exerts anti-inflammatory activities in a rat airway inflammation model. Eur J Pharmacol. 2019;849:2229.

115. Kannan K, Kanabar P, Schryer D, et al. The general mode of translation inhibition by macrolide antibiotics. P Natl Acad Sci U S A. 2014;111(45):15958-63.

116. Lu S, Liu H, Farley JM. Macrolide antibiotics inhibit mucus secretion and calcium entry in Swine airway submucosal mucous gland cells. J Pharm Exp Ther. 2011;336(1):178-187.

117. Nagashima A, Shinkai M, Shinoda M, et al. Clarithromycin Suppresses Chloride Channel Accessory 1 and Inhibits Interleukin-13-Induced Goblet Cell Hyperplasia in Human Bronchial Epithelial Cells. Antimicrob Agents Ch. 2016;60(11):6585-6590.

118. Shimizu T, Shimizu S, Hattori R, et al. In vivo and in vitro effects of macrolide antibiotics on mucus secretion in airway epithelial cells. Am J Respir Crit Care Med. 2003;168(5):581-587.

119. Tanabe T, Kanoh S, Tsushima K, et al. Clarithromycin inhibits interleukin-13-induced goblet cell hyperplasia in human airway cells. Am J Respir Cell Mol Biol. 2011;45(5):1075-1083.

120. PC B. Classification of agents that act on bronchial mucus. Drugs in Bronchial Mucology New York, Raven Press 1989.

121. Disse BG, Ziegler HW. Pharmacodynamic mechanism and therapeutic activity of ambroxol in animal experiments. Respiration. 1987;51 (Suppl 1):15-22. 
122. Seagrave J, Albrecht $\mathrm{HH}$, Hill DB, et al. Effects of guaifenesin, $\mathrm{N}$-acetylcysteine, and ambroxol on MUC5AC and mucociliary transport in primary differentiated human tracheal-bronchial cells. Respir Res. 2012;13:98.

123. Ge L-t, Liu Y-n, Lin X-x, et al. Inhalation of ambroxol inhibits cigarette smoke-induced acute lung injury in a mouse model by inhibiting the Erk pathway. Int Immunopharmacol. 2016;33:9098.

124. Zhang S-j, Jiang J-x, Ren Q-q, et al. Ambroxol inhalation ameliorates LPS-induced airway inflammation and mucus secretion through the extracellular signal-regulated kinase 1/2 signaling pathway. Eur J Pharmacol. 2016;775:138-148.

125. Brown DT. Carbocysteine. Drug Intell Clin Pharm. 1988;22(7-8):603-608.

126. Martin R, Litt M, Marriott $C$. The effect of mucolytic agents on the rheologic and transport properties of canine tracheal mucus. Am Rev Respir Dis. 1980;121(3):495-500.

127. Majima Y, Hirata K, Takeuchi K, et al. Effects of orally administered drugs on dynamic viscoelasticity of human nasal mucus. Am Rev Respir Dis. 1990;141(1):79-83.

128. Rogers DF, Turner NC, Marriott C, et al. Oral N-acetylcysteine or S-carboxymethylcysteine inhibit cigarette smoke-induced hypersecretion of mucus in rat larynx and trachea in situ. Eur Respir J. 1989;2(10):955-960.

129. Zheng J-P, Kang J, Huang S-G, et al. Effect of carbocisteine on acute exacerbation of chronic obstructive pulmonary disease (PEACE Study): a randomised placebo-controlled study. Lancet. 2008;371(9629):2013-2018.

130. Dechant KL, Noble S. Erdosteine. Drugs. 1996;52(6):875-881.

131. Hillas G, Nikolakopoulou S, Hussain S, et al. Antioxidants and mucolytics in COPD management: when (if ever) and in whom? Curr Drug Targets. 2013;14(2):225-234.

132. Dal Negro RW, Wedzicha JA, Iversen M, et al. Effect of erdosteine on the rate and duration of COPD exacerbations: the RESTORE study. Eur Respir J. 2017;50(4).

133. Marchioni CF, Polu JM, Taytard A, et al. Evaluation of efficacy and safety of erdosteine in patients affected by chronic bronchitis during an infective exacerbation phase and receiving amoxycillin as basic treatment (ECOBES, European Chronic Obstructive Bronchitis Erdosteine Study). Int J Clin Pharmacol Ther. 1995;33(11):612-618.

134. Marchioni CF1, Polu JM, Taytard A, et al. Evaluation of efficacy and safety of erdosteine in patients affected by chronic bronchitis during an infective exacerbation phase and receiving amoxycillin as basic treatment (ECOBES, European Chronic Obstructive Bronchitis Erdosteine Study). Int J Clin Pharmacol Ther. 1995;33(11):612-618.

135. Sadowska AM, Manuel-Y-Keenoy B, De Backer WA. Antioxidant and anti-inflammatory efficacy of NAC in the treatment of COPD: discordant in vitro and in vivo dose-effects: a review. Pulm Pharmacol Ther. 2007;20(1):9-22.

136. Cotgreave IA, Eklund A, Larsson K, et al. No penetration of orally administered Nacetylcysteine into bronchoalveolar lavage fluid. Eur J Respir. 1987;70(2):73-77.

137. Dano G. Bronchospasm caused by acetylcysteine in children with bronchial asthma. Acta All. 1971;26(3):181-90.

138. Decramer M, Rutten-van Mölken M, Dekhuijzen PNR, et al. Effects of N-acetylcysteine on outcomes in chronic obstructive pulmonary disease (Bronchitis Randomized on NAC CostUtility Study, BRONCUS): a randomised placebo-controlled trial. Lancet. 2005;365(9470):1552-1560.

139. Schermer T, Chavannes N, Dekhuijzen R, et al. Fluticasone and N-acetylcysteine in primary care patients with COPD or chronic bronchitis. Res Med. 2009;103(4):542-551.

140. Tse HN, Raiteri L, Wong KY, et al. High-dose N-acetylcysteine in stable COPD: the 1-year, double-blind, randomized, placebo-controlled HIACE study. Chest. 2013;144(1):106-118.

141. Black PN, Morgan-Day A, McMillan TE, et al. Randomised, controlled trial of N-acetylcysteine for treatment of acute exacerbations of chronic obstructive pulmonary disease [ISRCTN21676344]. BMC Pulm Med. 2004;4:13. 
142. Rubin BK. Secretion properties, clearance, and therapy in airway disease. Transl Res Med. 2014;2:6.

143. Fuchs HJ, Borowitz DS, Christiansen DH, et al. Effect of aerosolized recombinant human DNase on exacerbations of respiratory symptoms and on pulmonary function in patients with cystic fibrosis. The Pulmozyme Study Group. N Engl J Med. 1994;331(10):637-642.

144. Bone RC. A piece of my mind. Another 'taste of lemonade'. JAMA. 1995;274(21):1656.

145. Fiel MI, Min A, Gerber MA, et al. Hepatocellular carcinoma in long-term oral contraceptive use. Liver. 1996;16(6):372-376.

146. Ha EVS, Rogers DF. Novel Therapies to Inhibit Mucus Synthesis and Secretion in Airway Hypersecretory Diseases. Pharmacology. 2016;97(1-2):84-100.

147. Nie YC, Wu H, Li PB, et al. Characteristic comparison of three rat models induced by cigarette smoke or combined with LPS: to establish a suitable model for study of airway mucus hypersecretion in chronic obstructive pulmonary disease. Pulm Pharmacol Ther. 2012;25(5):349-356.

148. Yamada N, Nishida Y, Yokoyama S, et al. Expression of MUC5AC, an early marker of pancreatobiliary cancer, is regulated by DNA methylation in the distal promoter region in cancer cells. J Hepatobiliary Pancreat Sci. 2010;17(6):844-854.

149. Samsuzzaman M, Uddin MS, Shah MA, et al. Natural inhibitors on airway mucin: Molecular insight into the therapeutic potential targeting MUC5AC expression and production. Life sciences. 2019;231:116485. 


\section{Abbreviations}

AB

AGR2

ALI

AP-1

BAL

Bcl-2

BD

CA-125

CFTR

CLCA1

COPD

DNMTs

DNA

Dnase

EGF

EGFR

EGFR-TK

ERK

FEF

FEV $_{1}$

Fuc

FUT2

FVC

Gal

GalNac

GALNTS alcian blue

anterior gradient protein 2 homolog

air-liquid interface

activating protein 1

bronchoalveolar lavage

B-cell lymphoma 2

bronchodilator

cancer antigen-125

cystic fibrosis transmembrane conductance regulator

calcium-activated chloride channel-1

chronic obstructive pulmonary disease

DNA methyltransferases

deoxyribonucleic acid

deoxyribonuclease

epidermal growth factor

epidermal growth factor receptor

EGFR tyrosine kinase

extracellular signal-regulated kinases

forced expiratory flow

forced expiratory volume in the $1 \mathrm{st}$ second

fucose

galactoside 2-alpha-L-fucosyltransferase 2

forced vital capacity

galactose

$\mathrm{N}$-acetylgalactosamine

GalNAc-transferase 


\begin{tabular}{|c|c|}
\hline GCA & global clinical assessment \\
\hline GlcNac & $\mathrm{N}$-acetylglucosamine \\
\hline $\mathrm{H}_{2} \mathrm{O}_{2}$ & hydrogen peroxide \\
\hline HBEC & human bronchial epithelial cell \\
\hline HDACs & histone deacetylase \\
\hline HIF & hypoxia-inducible factors \\
\hline hNECs & human nasal epithelial cells \\
\hline HSP & heat shock protein \\
\hline $\mathrm{H} \& \mathrm{E}$ & haematoxylin and eosin \\
\hline IAV & influenza A virus \\
\hline IC & inspiratory capacity \\
\hline ICAM-1 & intercellular adhesion molecule 1 \\
\hline IKB & inhibitor of kappa B \\
\hline IKK & IKB kinase \\
\hline IL & interleukin \\
\hline IPF & idiopathic pulmonary fibrosis \\
\hline IRAK1 & interleukin-1 receptor-associated kinase 1 \\
\hline JAK & janus kinases \\
\hline LPS & lipopolysaccharide \\
\hline MAPK & mitogen-activated protein kinase-13 \\
\hline MARCKS & myristoylated alanine-rich $\mathrm{C}$ kinase substra \\
\hline mRNA & messenger ribonucleic acid \\
\hline miRNA & micro RNAs \\
\hline MS or VNTR & minisatellites \\
\hline MS & minisatellites \\
\hline MUC & mucin \\
\hline Munc-18 & mammalian uncoordinated-18 \\
\hline
\end{tabular}


MyD88

NANA

NAC

NAR

NeuNAc

NIK

$N F-\kappa B$

NSF

NTHi

PAF

PAS

PI3K

p-y

ROS

RSV

RUNX2

RV

Ser

SIGLEC

SNP

SPAP

SPDEF

ST3GAL3

STAT

STP

STR myeloid differentiation primary response 88

$\mathrm{N}$-acetyl neuraminic acid

$\mathrm{N}$-acetylcysteine

non-allergic rhinitis

$\mathrm{N}$-acetyl neuraminic acid

NF-kB-inducing kinase

nuclear factor kappa-light-chain-enhancer of activated B cells

soluble $\mathrm{N}$-ethylmaleimide-sensitive factor

non-typeable $\mathrm{H}$. Influenzae

platelet-activating factor

Periodic acid-Schiff

phosphatidylinositol 3-kinase

pack-years

reactive oxygen species

respiratory syncytial virus

runt-related transcription factor 2

rhinoviruse

serine

sialic acid-binding immunoglobulin-type lectins

single-nucleotide polymorphism

systolic pulmonary artery pressure

sterile a-motif-pointed domain-containing Ets-like factor,

ST3 beta-galactoside alpha-2,3-sialyltransferase 3

signal transducer and activator of transcription proteins

serine, threonine, and proline

short tandem repeats 
TAK

TAPSE

TGF- $\beta$

Thr

TLR

TNFa

THP-1 cells

TRAF6

UDP

VIP

VNTR
TGF- $\beta$-activated kinase

tricuspid annular plane systolic excursion

transforming growth factor- $\beta$

threonine

toll-like receptor

tumor necrosis factor $\alpha$

human monocytic cell line

TNF receptor associated factor

uridine diphosphate

vasoactive intestinal peptide.

variable number of tandem repeats or microsatellites 
Table 1. Mucins expressed in the lower airways of normal subjects

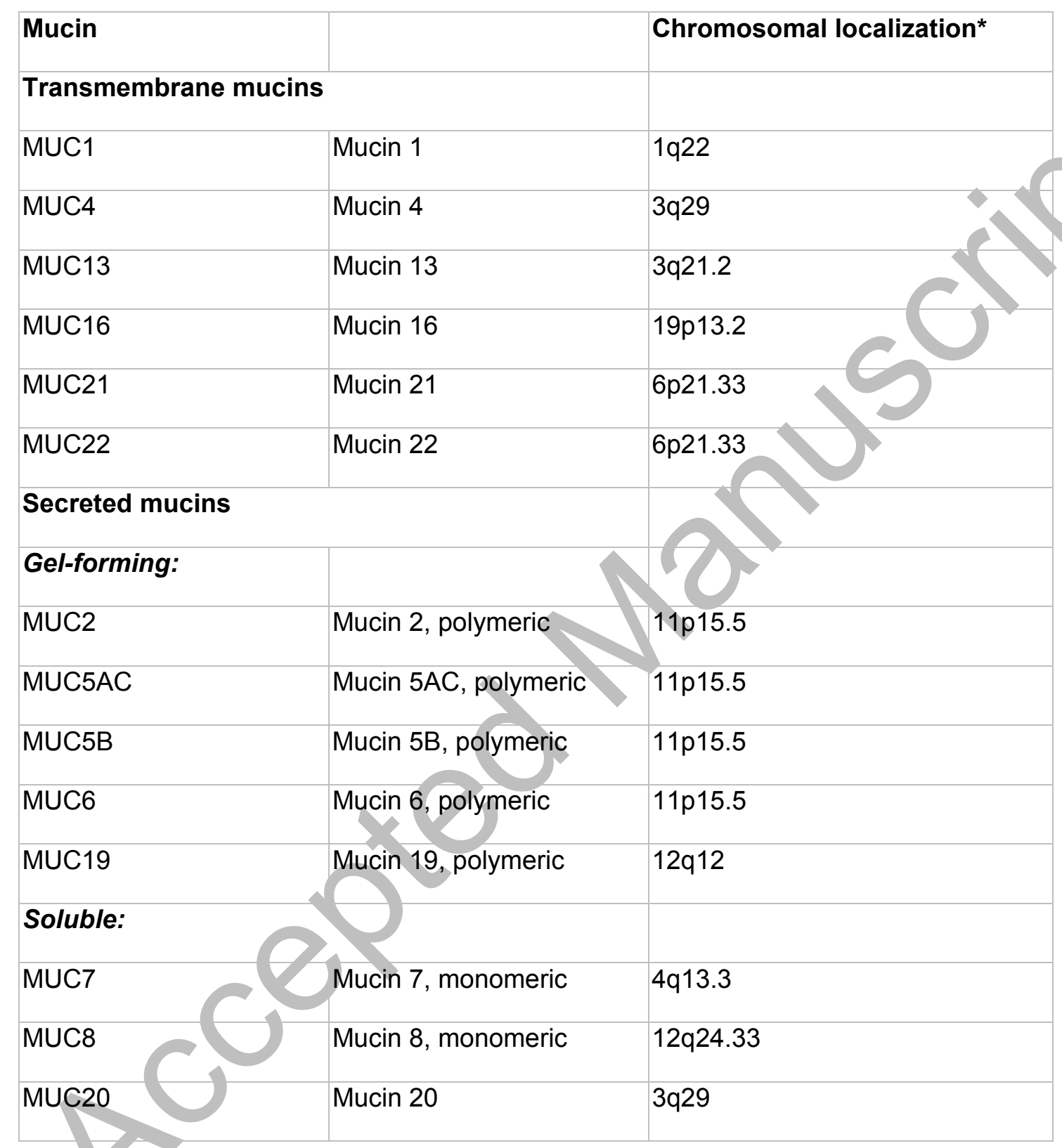

*Obtained with the data from OMIM (www.omim.org) and the references quoted in the text. 
Table 2. Steps in the synthesis, assembly, storage and secretion of the major secreted polymeric mucins MUC5AC and MUC5B of the human lower airways

\begin{tabular}{|c|c|c|}
\hline $\begin{array}{l}\text { Step } \\
\text { number }\end{array}$ & Process & Cellular and extracellular compartments \\
\hline 1 & Mucin synthesis & Endoplasmic reticulum \\
\hline 2 & Mucin polymerisation & Endoplasmic reticulum \\
\hline 3 & Mucin N- glycosylation & Endoplasmic reticulum \\
\hline 4 & Mucin C-mannosylation & Endoplasmic reticulc \\
\hline 5 & Mucin O-glycosylation & cis- and mes \\
\hline 6 & Granule condensation & and \\
\hline 7 & Granule packaging & trong Cola \\
\hline 8 & $\begin{array}{l}\text { Mucin granules secretion } \\
\text { and exocytosis }\end{array}$ & Apical areas of the cell \\
\hline 9 & Exocytosis & Plasma membrane \\
\hline 10 & $\begin{array}{l}\text { Mucin modifications post- } \\
\text { exocytosis }\end{array}$ & Extracellular space \\
\hline
\end{tabular}

Obtained with the data from [3] 
Table 3. Epigenetic pathways modulating the synthesis/secretion of the major secreted polymeric mucins MUC5AC and MUC5B of the human lower airways

\begin{tabular}{|l|l|l|l|}
\hline $\begin{array}{l}\text { Epigenetic } \\
\text { pathways }\end{array}$ & Enzyme & $\begin{array}{l}\text { Transcription } \\
\text { factors involved }\end{array}$ & $\begin{array}{l}\text { Effect on MUC5AC } \\
\text { and/or MUC5B }\end{array}$ \\
\hline DNA methylation & DNMTs & $\downarrow$ SPDEF & $\downarrow$ \\
\hline $\begin{array}{l}\text { Histone } \\
\text { deacetylation }\end{array}$ & HDACs & $\downarrow$ NF-KB & $\downarrow$ \\
\hline & $\downarrow$ AP-1 & \\
\hline
\end{tabular}

*AP-1: activator protein 1, DNMTs: DNA methyltransferases, HDACs: histone deacetylase, NF- B: nuclear factor kappa-light-chain-enhancer of activated B cells, SPDEF: sterile a-motif-pointed domain-containing Ets-like factor,

Obtained with the data from $[74,139,140]$. 
Table 4. Inflammatory mediators and infectious agents up-regulating the synthesis/secretion of mucins from primary tracheobronchial epithelium obtained from normal subjects in vitro

\begin{tabular}{ll}
\hline Inflammatory mediators & Infectious agents \\
\hline Acetylcholine & Influenza viruses \\
\hline Bradykinin and EGF & Respiratory syncytial virus \\
\hline Cytokines (IL-1 $\beta$, IL-6, IL-13, IL-17, IL-36y, TNFa) & Rhinovirus \\
\hline Endothelins & Haemophilus influenzae \\
\hline Neuropeptides (tachykinins and VIP) & Pseudomonas aeruginosa \\
\hline Neutrophil defensins & Streptococcus pneumoniae \\
\hline Proteases (trypsin, neutrophil elastase) & \\
\hline ROS & \\
\hline
\end{tabular}

Only the major inflammatory mediators and infectious agents considered relevant to the pathogenesis of COPD are included.

*EGF: epidermal growth factor, IL: interleukin, ROS: reactive oxygen species, TNFa: tumour necrosis factor $\alpha$, VIP: vasoactive intestinal peptide.

Obtained with data from: $[20,23,24]$ 
Table 5. Physiological functions of mucins of human lower airways

\begin{tabular}{|c|c|}
\hline Mucins in mucociliary clearance & $\begin{array}{l}\text { Mucins in immune defences of the human lower } \\
\text { airways }\end{array}$ \\
\hline $\begin{array}{l}\text { Protection of lower airway epithelium } \\
\text { from particles and micro-organisms }\end{array}$ & $\downarrow$ Neutrophilic inflammation \\
\hline $\begin{array}{l}\text { Organizing the framework of the } \\
\text { mucus gel in the lower airways }\end{array}$ & $\downarrow$ Macrophage function \\
\hline Creation of an osmotic barrier & $\downarrow$ Eosinophil function (Siglec-8) \\
\hline \multirow[t]{6}{*}{ Prevention of mucus dehydration } & $\downarrow$ Neutrophil function (Siglec-9) \\
\hline & $\downarrow$ Pro-inflammatory cytokines \\
\hline & Suppression of virulence of opportunistic pathogens \\
\hline & Promotion of stable microbiota \\
\hline & Direct interaction with pathogens (surface glycans) \\
\hline & $\begin{array}{l}\text { Protection of surface epithelium from biofilm } \\
\text { formation by pathogens }\end{array}$ \\
\hline
\end{tabular}

* Siglec: sialic acid-binding immunoglobulin-type lectins

Obtained with the data from [18]. 
Table 6. Novel potential compounds for the treatment of COPD patients acting on mucin synthesis/secretion/structure

\begin{tabular}{|c|c|c|}
\hline Compounds & Natural products & Process involved \\
\hline $\begin{array}{l}\text { Bcl-2 antagonists } \\
\text { CLCA1inhibitors } \\
\text { EGFR-TK inhibitorsHIF-1 } \\
\text { inhibitors } \\
\text { MAPK13 inhibitors } \\
\text { Monoclonal antibodies against the } \\
\text { EGFR }\end{array}$ & $\begin{array}{l}\begin{array}{l}\text { Naturally derived alkaloids } \\
\text { (berberine) }\end{array} \\
\text { Naturally derived flavonoid } \\
\text { (curcumin, gingerol, kaempferol, } \\
\text { ginseng, luteolin) } \\
\text { Naturally derived glycosides } \\
\text { Naturally derived steroids }\end{array}$ & Mucin synthesis \\
\hline $\begin{array}{l}\text { HSP-70 inhibitors } \\
\text { Munc-18 inhibitors } \\
\text { MARCKS blockade } \\
\text { NSF attachment protein receptors } \\
\text { cleavage }\end{array}$ & & $\begin{array}{lr}\text { Mucin } & \text { granules } \\
\text { secretion } & \text { and } \\
\text { exocytosis } & \end{array}$ \\
\hline $\begin{array}{l}\text { Antagomirs } \\
\text { Bcl-2 antagonist }\end{array}$ & Ellagic acid & $\begin{array}{l}\text { Mucin-secreting } \\
\text { cells hyperplasia }\end{array}$ \\
\hline
\end{tabular}

* Bcl-2: B-cell lymphoma 2; CLCA1: calcium-activated chloride channel-1; EGFR-TK: EGFR tyrosine kinase; HIF: hypoxia-inducible factors; HSP: heat shock protein; MAPK13: mitogenactivated protein kinase-13; MARCKS: myristoylated alanine-rich $C$ kinase substrate; Munc-18: mammalian uncoordinated-18; NSF: soluble N-ethylmaleimide-sensitive factor

Obtained with data from $[138,141]$. 
Figure 1. Schematic of the mucin (MUC) protein backbone and its O-glycans. The MUC protein backbone typically consists of an $\mathrm{NH} 2$-terminal domain, one or more central domain(s) with a high number of tandem repeat (TR) domains, and a $\mathrm{COOH}$-terminal domain with many O-glycans that exhibit size heterogeneity attached to threonine or serine residues in the TR domains.

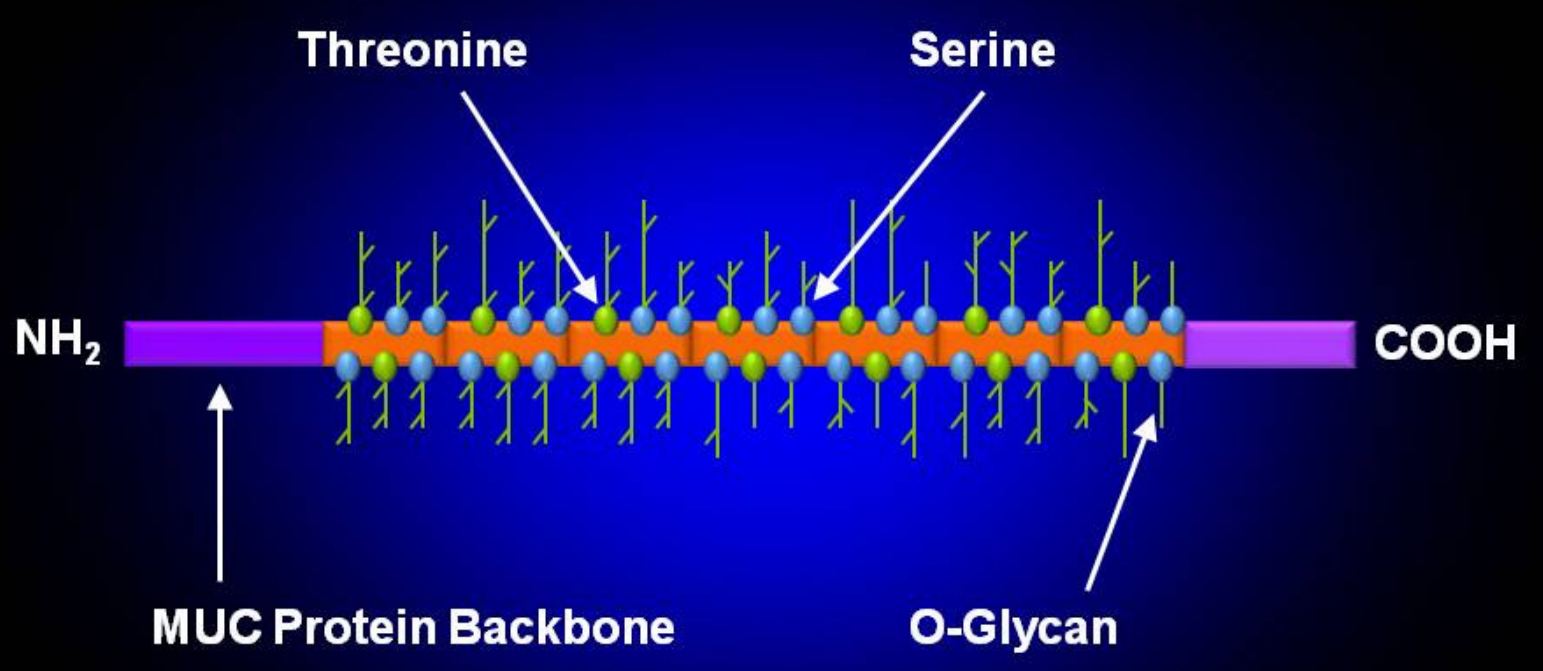

